\title{
Varieties of Political Support in Emerging Democracies: A Cross-National Analysis
}

\author{
Gabriel Katz ${ }^{* 1}$ and Ines Levin ${ }^{\dagger 2}$ \\ ${ }^{1}$ Politics Department, University of Exeter \\ ${ }^{2}$ Department of Political Science, University of California, Irvine
}

August 11, 2017

\begin{abstract}
Political support is a multidimensional construct encompassing evaluations of political leaders and institutions (specific support) as well as adherence to basic regime principles (diffuse support). Scholars have traditionally assumed that diffuse and specific support are driven by different forces and evolve largely independently. Prior empirical work, however, has struggled to untangle the two support dimensions and focused predominantly on cross-national differences, ignoring their dynamics. This paper develops an analytical and empirical approach to examine the levels and dynamic interplay of both support dimensions and estimate their determinants, applying it to South American democracies between 1996 and 2015. Contrary to received wisdom, we show that both dimensions are quite volatile and closely linked in this region. In particular, negative economic shocks not only undermine support for government actors, but also fuel democratic disenchantment. Nonetheless, while regime support is rather fickle in South America, it can be ultimately resistant to performance fluctuations.
\end{abstract}

Keywords: Political Support, Latin American politics, Machine Learning, Latent Class Analysis, Bayesian Inference.

\footnotetext{
*Ph.D., Senior Lecturer, Department of Politics, University of Exeter. email address: G.Katz@exeter.ac.uk.

${ }^{\dagger}$ Ph.D., Assistant Professor, Department of Political Science, University of California, Irvine. email address: i.levin@uci.edu.
} 


\section{Introduction}

Starting from Easton (1965)'s seminal work, a large body of literature has highlighted the multidimensional nature of political support, recognizing that individual citizens may be "(...) more or less supportive of each dimension" (Booth and Seligson, 2009: 10). In particular, citizens may display different levels of diffuse support for the core values and procedures embodied in the political regime, as well as varying degrees of specific support for public officials and institutions.

The notions of diffuse and specific support are neither observationally nor conceptually equivalent. The latter is circumscribed to specific office-holders or government bodies, and based on evaluations of their actions and decisions. The diffuse dimension, on the other hand, is seen as determined by deeply-held attachments to democratic values and norms (Easton, 1965). Traditionally, scholars have posited that these two dimensions are only loosely connected. While specific support is deemed to shift constantly in response to the policies and outputs produced by the political system, support for regime principles is assumed essentially impervious to short-term changes in performance or contextual circumstances (Easton, 1975).

The two support dimensions, however, are likely to be more closely intertwined in new or consolidating democracies. In societies without a vast reservoir of diffuse support to help tide over hard times, the political system's inability to respond to citizens' demands may not only undermine trust in politicians and authoritative institutions, but also erode confidence in democratic ideals. In such contexts, economic downturns or disappointing policy outcomes - which in more established polities would simply prompt voters to punish incumbents at the ballot box - may lead citizens to question not only the competence of elected officials or the effectiveness of the state apparatus, but also the regime's legitimacy (Katz and Levin, 2016).

Is diffuse support in emerging democracies more volatile than previously assumed? Do the diffuse and specific dimensions respond to similar forces in these settings? More concretely, do policy failures or poor - e.g., economic - performances "flow upwards," affecting not only specific support for those responsible for these outcomes 
but also popular outlooks towards democracy? How does the connection between such critical junctures and the two support dimensions vary across individuals, polities, and over time? Answering these questions requires taking into consideration the multifaceted and dynamic character of political support, discriminating between its components while still accounting for their potential co-variation. Furthermore, as noted by Gilley (2009), a long-term perspective is necessary to understand whether swings in diffuse and specific support reflect trendless oscillations or structural breaks.

Prior research, however, has struggled to deal with the multidimensional nature of support and to disentangle its components using standard survey instruments predominant in empirical work (Gershtenson and Plane, 2012). In addition, most comparative studies have focused solely on explaining cross-national variations, largely ignoring the temporal dimension (Bargsted, Somma, and Castillo, 2017). To overcome these shortcomings, we develop a novel analytical framework and empirical strategy to study political support. Our approach distinguishes substantively meaningful "types" of citizens based on their underlying support for political actors and institutions as well as on their adherence to regime principles, employing a two-step method to classify individuals into these categories and examine the correlates of support. The first step integrates Bayesian latent class analysis and supervised machine learning to identify survey respondents' positions on the two support dimensions. In the second step, we simultaneously estimate the individual and contextual determinants of type assignment and contrast their influence on each dimension. We can thus identify groups of citizens that vary in their levels of diffuse and specific support and uncover the key factors explaining their prevalence and evolution.

We apply our approach to the analysis of political support in South America between 1996 and 2015. Roughly thirty years after the "third wave of democratization," attitudes towards political elites and commitment to democratic tenets vary dramatically within this region (Booth and Seligson, 2009). Along with these disparities in mass political opinions, South American countries exhibit substantial differences in institutional features, regime performance and socio-demographic characteristics, 
allowing an in-depth examination of rival explanations of support while keeping unobservable - e.g., cultural - factors relatively constant. Our analysis also sheds light on the short- and long-term impact of the economic and political changes experienced by the subcontinent over the last two decades, marked by cyclical alternations of booms and recessions and the collapse of several countries' party systems (Mainwaring, 2006). Examining the temporal response curves of diffuse and specific support to these events provides valuable insights into the dynamic interplay between both dimensions, addressing an important lacuna in the field.

\section{Varieties of Political Support: Typology and De- terminants}

Our classification of varieties of political support builds on Easton (1965)'s distinction between diffuse support for democratic principles and specific support for political actors and institutions. The combination of the two support dimensions makes possible a simple categorization of individuals' assessments of fundamental and functional aspects of democracy. As seen in Table 1, this classification defines four types of citizens, which we label satisfied democrats, dissatisfied democrats, anti-system and alienated. The typology can be justified both theoretically and empirically.

Table 1: Dimensions and Types of Support

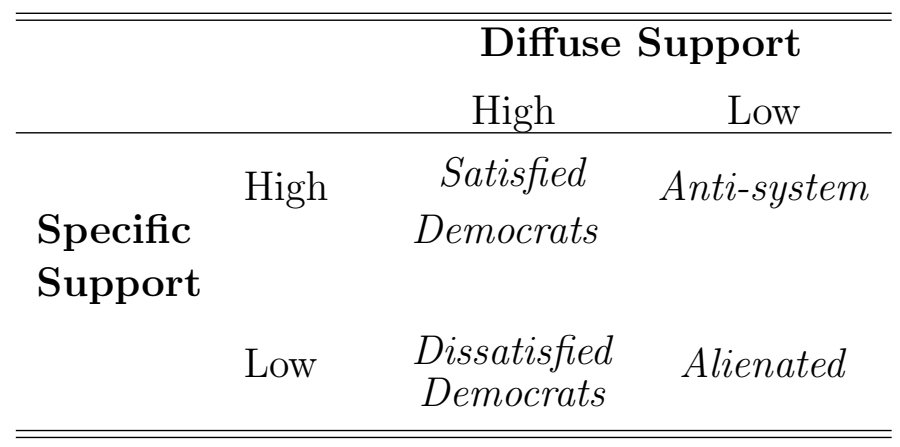

The distinction between satisfied and dissatisfied democrats, which captures differences in attitudes towards the actors and institutions of the political system among 
citizens with high levels of attachment to democratic norms, is grounded on prior work within the Eastonian theoretical framework. Klingemann (1999) tags citizens who are convinced democrats but nonetheless critical of the workings of the democratic process as "dissatisfied democrats." The same basic notion underlies Norris (1999)'s conceptualization of "critical citizens" and Linde (2004)'s definition of "doubtful democrats." Drawing on this tradition, we classify individuals with high levels of diffuse support but low levels of specific support as dissatisfied democrats, while satisfied democrats refers to those who score high on the two dimensions.

Because much of this pioneering literature focused on established democracies, where adherence to the democratic ideal is nearly universal (Klingemann, 1999; Norris, 1999), the types in the second column of Table 1 have been subject to less theoretical development. Nevertheless, baseline diffuse or regime support can be quite limited in some fledgling democracies. For instance, only slightly more than half of South Americans at the turn of the century agreed that democracy was the best form of government (Hagopian, 2005). ${ }^{1}$

Low levels of diffuse support are not incompatible with strong support for specific political actors, though. In fact, "anti-system appeals" (Hagopian, 2005: 354) from politicians with dubious democratic credentials are likely to mobilize mass support in these settings, as illustrated by the recent history of several South American countries. In Peru, Fujimori's decision to dissolve Congress and suspend the Constitution in 1992 was backed by a large segment of the population, who saw him as an effective leader capable of curbing hyperinflation and defeating the guerrilla insurgency something deemed impossible within the constraints of democratic politics (Levitsky and Cameron, 2003). Similarly, the 2002 election in Ecuador brought Lucio Gutiérrez into office, an army colonel who few years earlier had led a revolt against a discredited but constitutional government. More generally, the rise to power of candidates like Hugo Chávez in Venezuela or Evo Morales in Bolivia reveals that citizens may support certain political figures - and the government bodies created or co-opted by

\footnotetext{
${ }^{1}$ The corresponding figure in established democracies was above $90 \%$ (Klingemann, 1999).
} 
them - despite their apparent disregard for democratic procedures. This is the type of "anti-system views" (Dalton, 1999: 75) we would find in the upper-right corner of Table 1. Of course, people disillusioned with democracy may also disapprove of all politicians and representative institutions. Following Torcal and Montero (2006), we tag these individuals with low levels of both diffuse and specific support as alienated. ${ }^{2}$

Together, the distribution of the four types of citizens will determine the aggregate levels of diffuse and specific support in a polity and condition their evolution over time. In this direction, the preponderance of anti-system types may not only facilitate the success of leaders with questionable attitudes toward democracy, but also embolden them to dismantle checks and balances and further corrode the regime's foundations. At the other extreme, where satisfied or even dissatisfied democrats predominate, regime support is more likely to be inoculated from temporary flaws in the functioning of the institutions of political representation.

\subsection{Correlates of support types}

What are the macro- and micro-level factors that determine whether an individual is a satisfied or dissatisfied democrat, whether she turns to anti-system options or becomes politically alienated? Previous work identified three main explanations for crossnational and temporal variations in political support: institutional, performancebased, and socio-demographic (Norris, 1999; Segovia, 2008). ${ }^{3}$

The first explanation maintains that political support is primarily a function of institutional arrangements. Two aspects of the institutional design figure prominently in the literature: the overall quality of democratic institutions, and the nature of the mechanisms linking public preferences to the political decision-making process - above all, the electoral rules and the characteristics of the party system (Freitag

\footnotetext{
${ }^{2}$ These authors draw a distinction between political disaffection and alienation, arguing that the former implies a general distrust of politics but not, like the latter, a critical view of democracy.

${ }^{3}$ Some authors also emphasize the relevance of "culture" in molding political support, although others downplay its significance (Mishler and Rose, 2005). Operationalizing cultural values for empirical analysis is notoriously difficult, since these are fundamentally unmeasurable. We sidestep this issue by studying countries with similar cultural backgrounds while accounting for the geographical and temporal correlation of political opinions.
} 
and Bühlmann, 2009; Norris, 1999). Norris (1999) contends that regime support is stronger in countries with "better democracies." Although measuring the quality of democracy is far from straightforward, the protection of political and civil rights are basic democratic tenets, and the extent to which they are guaranteed in practice is an indicator of the level of democratization of a polity (Booth and Seligson, 2009). Following this logic, safeguarding these rights is not only intrinsically valuable, but also instrumental in preserving and enhancing diffuse support (Payne, Zovato, and Mateo, 2007). Additionally, extant research indicates that in countries where political opposition is censored, rights to protest limited and law enforcement unable to prevent (political) actors from abusing their position, people tend to be more cynical about incumbents and the operation of state entities as well (Hagopian, 2005).

Scholars also agree that institutional configurations that allow a broader set of societal interests to be represented in the decision-making process and that promote accountable and responsive governance are likely to foster confidence in authorities and government bodies. In this sense, and building on Freitag and Bühlmann (2009), satisfaction with the workings of democracy is expected to be positively correlated with the proportionality of the electoral system. If citizens believe that the rules of the democratic game allow adequate representation of their interests, they may develop greater faith in the system and its outcomes (Norris, 1999). But the effectiveness of the political system and public satisfaction with its performance may suffer if proportionality coincides with a highly fragmented party system. Norris (1999) argues that political support will be highest in multi-party systems that present citizens with a reasonable range of policy choices, enabling them to effectively use elections to "throw the rascals out" while avoiding political stalemate.

Besides the number of parties, their institutionalization may affect assessments of the functioning of the political system as well. Strong and stable parties make democracy "workable," facilitating governability and rendering it easier for voters to hold public officials accountable. More generally, institutionalized party systems play a key role channeling political discontent and limiting the space available to 
anti-system candidates (Levitsky and Cameron, 2003). By contrast, when parties are weak or non-institutionalized, competing or conflicting interest may fail to find representation in the electoral arena, and citizens might choose to back non-democratic alternatives instead.

While these institutional features tend to be persistent and thus expected to account for cross-national differences in levels of support at given moments in time, performance-based explanations are better suited to account for changes in support occurring over time. The vast retrospective voting literature (see Lewis-Beck and Stegmaier, 2000, and the references therein) has demonstrated that public judgments of political leaders are strongly correlated with their (real or perceived) ability to manage the economy, as captured by objective macro-economic indicators - per capita GDP, growth, unemployment, inflation - as well as by subjective measures of economic satisfaction. Performance, however, need not be narrowly defined in purely economic terms. Social policy outcomes and the outputs of the welfare state, for instance, also impinge on opinions about the political system's capacity to protect its citizens and meet popular demands - e.g., for public goods and socio-economic inclusion (Freitag and Bühlmann, 2009; Mainwaring, 2006). Although performance-based evaluations are intrinsic to Easton (1965)'s definition of specific support, Katz and Levin (2016) show that disappointing policy outcomes can sometimes erode support for democracy - especially in post-transitional regimes, where the "reservoir of good will" that helps build tolerance for performance deficits is typically shallower.

Based on these arguments, then, satisfied democrats should prevail in contexts in which political and civil liberties are protected, institutional arrangements enhance opportunities for political participation while overcoming gridlock, and governments are able solve their citizens' most pressing problems. Dissatisfied democrats, in turn, should be relatively more plentiful where basic democratic rights are effectively guaranteed but power-sharing agreements are less equitable, the political system is unresponsive or ineffective, and authorities are unable to promote the general welfare and provide people with key economic and social resources. Where both the legal- 
institutional framework and political establishment are weak and elites are incapable of successfully administering economic and social policy, anti-system and alienated types should be more common. Their relative weight would depend on the severity of the political system's under-performance and its power to resist the encroachment of anti-party outsiders promising to fulfill neglected needs.

Individuals' political beliefs and personal traits also color their evaluations of fundamental and functional aspects of democracy. Listhaug (1995) finds that citizens who are politically close to the incumbents are more likely to support officeholders and government agencies than individuals affiliated to opposition candidates or parties. This is hardly a surprising result. However, ideological leanings can have implications for diffuse support as well: Seligson (2007) reports that, in Latin America, people who self-identify as leftist are less likely to favor democracy as the best form of government. In addition, better-educated individuals have been shown to be more likely to support democracy, but also more critical of politicians and government (Dalton, 2005; Magalhães, 2013). Social capital theory, in turn, has found that inter-personal trust correlates positively with confidence in representative institutions, although its relationship to diffuse support is more tenuous (Mishler and Rose, 2005). These individual characteristics will condition or moderate the influence of the contextual (institutional, performance-related) factors and, together, shape the distribution of support types and their dynamics within and between countries.

\section{Political Support in South America: Background and Context}

The countries covered in our analysis - Argentina, Bolivia, Brazil, Chile, Colombia, Ecuador, Paraguay, Peru, Uruguay and Venezuela - are all formally electoral democracies with constitutional separation of powers and presidential forms of government. Almost all of them - with the exceptions of Colombia and Venezuela - transitioned to democracy in the last 30 years, after the dictatorships of the 1970s and 1980s.

In the following decades, democracy became largely consolidated in some of these 
nations while enduring major threats and setbacks in others. Building on Mainwaring and Hagopian (2005), South American polities can be classified in four broad groups based on the overall quality of their democratic institutions. A first group comprises Chile and Uruguay, the two countries with the most ingrained and robust democratic traditions. Both nations had a legacy of well-functioning political and legal institutions and socially rooted parties that had managed to survive the dictatorial intermission, which facilitated the reconstruction of the political system and the recovery of public confidence in it (Jones, 2012).

In a second group we have Argentina and Brazil, two cases of "(..) surprising success in democratization" in view of their turbulent political histories and weak democratic track records (Mainwaring and Hagopian 2005: 10). Since 1983, Argentina has enjoyed the longest ever period of uninterrupted competitive elections. It is true that trust in state institutions plummeted between 2001 and 2003, when the country suffered one of the most severe recessions in its history. Still, Levitsky (2005) argues that the fact that the political system was able to weather the crisis without reverting to authoritarian patterns is proof of the resilience of Argentina's democracy. Brazil has also been able to sustain a relatively stable regime despite numerous challenges, such as the impeachments of Presidents Collor de Mello in 1992 and Dilma Rousseff in 2016, and - more recently - the popular outcry over the "Car Wash" corruption scandal. As pointed out by Weyland (2005), though, the political establishment has been able to solve or contain these crises within the institutional framework.

By contrast, the third group includes crisis-ridden polities that underwent episodes of near- or outright regime breakdown in the 1990s and 2000s. Mainwaring and Hagopian (2005) identify Fujimori's 1992 executive coup in Peru as the only clear example of authoritarian involution in the subcontinent. Episodes of political instability were also recurrent in Paraguay - including coup attempts in 1996 and 2000 and Ecuador, where three consecutive presidents were ousted between 1997 and 2005. In Bolivia, the process of institution-building initiated in the 1980s was brought to a halt in 2003, when the democratically elected president and his successor were forced 
to resign amidst a profound social and governability crisis. Democratic instability in Bolivia, Ecuador and Peru was accompanied by the collapse of the old party systems, paving the way to power of political outsiders governing in an anti-institutional manner (Mainwaring, 2006).

Venezuela fits the previous category in many respects. Nonetheless, like Colombia, it can be better depicted as an example of regime erosion, rather than breakdown. Once a vibrant and stable democracy, Venezuela experienced the demise of its long-standing but increasingly inefficient and unresponsive party system in the late 1990s. After Hugo Chávez was voted into office in 1998, mechanisms of democratic accountability were removed and all-encompassing powers concentrated in the president (Coppedge, 2005). In the case of Colombia, the decline in the quality of democracy can be traced to the state's inability to guarantee the constitutional order and safeguard civil liberties, as demonstrated by the country's appalling human rights record. Although the state's fragility has deep historical roots, governance problems were exacerbated after the 1991 Constitutional reform, which weakened executive power and undermined political representation at a time when drug lords and guerrilla groups intensified their siege of democracy (Bejarano and Pizarro, 2005).

The ten countries also display differences in their electoral systems. The rules to choose the head of state include plurality in Paraguay and Venezuela, majority runoff (in Bolivia, Brazil, Chile, Colombia, Peru and Uruguay), and runoff with reduced thresholds (i.e., below 50\%) in Argentina and Ecuador. For legislative elections, all the countries except Chile use some variant of proportional representation $(\mathrm{PR})$, with average district magnitudes ranging from 4.4 in Paraguay to 19 in Brazil. Chile adopted a form of majority ("binomial") system that favors the two largest parties competing for the two seats up for election in each district. These differences in electoral rules affect the representativeness and effectiveness of the political system, two aspects expected to influence diffuse and specific support.

As summarized in Table 2, PR systems with large district magnitudes like those in Bolivia, Brazil and Uruguay promote the most equitable representation of diverse 
Table 2: Legislative Electoral Systems, Disproportionality, Number of Parties and Policy-Making Effectiveness in South American Democracies

\begin{tabular}{|c|c|c|c|c|}
\hline Country & $\begin{array}{l}\text { Electoral rules } \\
\text { Lower House }\end{array}$ & 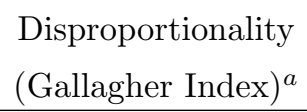 & $\begin{array}{c}\text { Effective number } \\
\text { of parties }\end{array}$ & $\begin{array}{c}\text { Policy-Making } \\
\text { Effectiveness }\end{array}$ \\
\hline Argentina & $\begin{array}{l}\mathrm{PR}, \text { medium-sized } \\
\text { districts }\end{array}$ & 7.58 & 3.80 & Low \\
\hline Bolivia & $\begin{array}{l}\text { Mixed-member PR } \\
\text { large districts }\end{array}$ & 4.65 & 5.14 & Low \\
\hline Brazil & $\mathrm{PR}$, large districts & 3.56 & 7.70 & Minimal \\
\hline Chile & $\begin{array}{l}\text { Majority ("Binomial"), } \\
\text { small districts }\end{array}$ & 6.72 & 2.43 & High \\
\hline Colombia & $\begin{array}{l}\mathrm{PR}, \text { medium-sized } \\
\text { districts }\end{array}$ & 5.24 & 3.34 & Low \\
\hline Ecuador & $\mathrm{PR}$, small districts & 8.50 & 7.21 & Low \\
\hline Paraguay & $\begin{array}{l}\mathrm{PR}, \text { medium-sized } \\
\text { districts }\end{array}$ & 6.80 & 2.69 & Low \\
\hline Peru & $\mathrm{PR}$, large districts & 9.14 & 4.61 & Low \\
\hline Uruguay & $\mathrm{PR}$, large districts & 0.94 & 3.19 & Low \\
\hline Venezuela & $\begin{array}{l}\text { Mixed-member PR } \\
\text { medium-sized districts }\end{array}$ & 7.89 & 4.42 & Low \\
\hline
\end{tabular}

Source: Author's compilation, based on Payne, Zovato, and Mateo (2007).

Notes: ${ }^{a}$ In lower house elections. Higher values indicate more disproportional systems.

${ }^{b}$ Based on votes in lower house elections.

interests in the political decision-making process. At the same time, they run the risk of fostering legislative atomization and rendering governing more difficult, especially when - as in Brazil - the number of parties with a realistic chance of obtaining seats is large. On the other hand, Chile's binomial system, which promotes a concentration of legislative seats, boosts policy-making effectiveness at the expense of proportionality.

Besides these politico-institutional differences, South American nations vary in their economic and socio-demographic characteristics. As shown in Table A.1 of the Online Appendix, the more robust or relatively successful democracies (Chile, Uruguay, Argentina and Brazil) are also the more economically developed. Towards 
the end of our sample period, GDP per capita in Chile was more than 5 times higher than in Bolivia, while the proportion of people living in poverty was 5 times lower. Variations in illiteracy and infant mortality were also substantial, indicating noticeable differences in states' investments in social welfare. For instance, infant mortality rates ranged from 7 and 8.7 per 1,000 births in Chile and Uruguay, respectively, to more than 30 in Bolivia. Nevertheless, the relationship between democratic quality and socio-economic indicators is not linear. Income distribution in Chile was more unequal than in crisis-ridden polities like Bolivia and Peru, whereas Venezuela's eroding democracy exhibited one of the lowest Gini coefficients in the region (0.40). The incidence of poverty was also higher in Argentina than in Ecuador or Paraguay, while Colombia and Peru had lower infant mortality and illiteracy rates than Brazil. Although the political deterioration in Venezuela has taken its toll on economic performance, Peru grew at an annual rate of 3.3\% over the sample period, faster than any of the more robust democracies. That said, growth was erratic in most countries, with recurrent accelerations and reversals (see Figure A.1 in the Online Appendix).

In sum, the countries under study differ markedly in their political, institutional and socio-economic features, more so than the widely researched industrialized nations (Booth and Seligson, 2009). The question of political support in South America, however, has received comparatively little academic attention (Bargsted, Somma, and Castillo, 2017), and thus our analysis allows exploring the relative weight and evolution of the different support types and their relationship to the explanatory factors underscored by prior research in a relatively new setting. In particular, South America provides an ideal scenario for testing performance-based accounts of political support. Hagopian (2005) maintains that poor government performance is the key source of political discontent in the region, and the reason why citizens are willing to back populist leaders with questionable faith in democratic mechanisms as long as they deliver - or promise to deliver - solutions to salient national problems. It is precisely under these conditions when one would expect the link between system performance and perceived regime legitimacy to be more pronounced (Norris, 1999). 
While satisfaction with the workings of democracy has declined in several industrialized nations as well (e.g., Holmberg, 1999), democracy as a form of government is overwhelmingly accepted in these more prosperous and stable polities, and thus the decline in support has been constrained to the "positive end" of the legitimacy scale (Booth and Seligson, 2009: 102). As we noted in Section 2, mean regime support is substantially lower in South America, and the gap between public expectations and system performance wider (Hagopian, 2005). In fact, perceived regime legitimacy is also lower on average in South America than in new Asian, African or Eastern European democracies (Doorenspleet, 2012; Fuchs and Roller, 2006; Rose, Shin, and Munro, 1999; Segovia, 2008). Hence, the consequences of mass political disaffection are potentially more pernicious for democratic stability. On the other hand, if diffuse support is relatively insensitive to performance deficiencies in this scenario, the destabilizing influence of government failures or disappointing policy outcomes should be even weaker in more solid (established and young) democracies.

Although some of the patterns discussed in this section may hold for Latin America in general, focusing on South America facilitates a more detailed consideration of their impact on support while avoiding gross extrapolations of localized trends to a diverse continent (Booth and Seligson, 2009). Concentrating on a moderate number of geographically contiguous states sharing similar historical and cultural origins also mitigates concerns about unobserved confounding and about the cross-national validity of the survey questions used in the analysis - which become more problematic as sample countries grow in size and diversity (Hallquist and Wright, 2014).

\section{Data and Methods}

Our empirical analysis uses data from the yearly surveys conducted in South America by the Latinobarometer public opinion project between 1996 and 2015. ${ }^{4}$ This is the longest public opinion time-series data available for South America, allowing us to track the evolution of political support for almost two decades. We analyzed items

\footnotetext{
${ }^{4}$ The first survey, conducted in 1995, did not cover Bolivia, Ecuador, or Colombia.
} 
included in all the surveys, yielding a sample size of $147,252 .{ }^{5}$ The individual data was matched to macro-level economic, political, and institutional indicators.

Our dependent variables are built from eight questions tapping into participants' trust in political actors and institutions, along with general attitudes toward democracy. The first six questions asked respondents their degree of confidence in Government, the President, the National Congress, the Political Parties, the Judiciary, and the Military. ${ }^{6}$ These items gauge trust in representative and implementation bodies (Rothstein and Stolle, 2008), and can be taken as indicators of support for both "(...) the specific political actors in charge of every institution and the overarching principles of democracy" (Zmerli, Newton, and Montero, 2007: 41).

The last two items assessed attitudes towards democratic performance and principles. One is the standard "satisfaction with democracy" (SWD) question asking respondents their level of satisfaction with the way democracy works in their country. Although this item has been widely used as a measure of diffuse support in the political science literature (e.g., Weitz-Shapiro, 2008), scholars have shown that it can also correlate with support for incumbents or government performance (Linde and Ekman, 2003). The other item asked participants whether they always preferred democracy to any other form of government; responses to this question provide a more unequivocal measure of general support for democracy (Weitz-Shapiro, 2008).

The independent variables comprise individual and contextual factors expected to influence the probability that respondents are classified into the four support types described in Section 2. Following the discussion in 2.1, the individual-level covariates include: subjective measures of economic satisfaction (evaluations of the national economy and personal finances, employment status and concerns); respondents' political orientations (self-placement on the left-right scale and spatial distance from the incumbent party); inter-personal trust; education; and other socio-demographic controls

\footnotetext{
${ }^{5}$ Additionally, a random sample of 49,084 observations was used for out-of-sample evaluation of our model's predictive accuracy.

${ }^{6}$ Other items measuring trust in the state, local government, the public administration and election authorities were available for specific years, but not for the entire sample period. We used these items to assess the content-validity of our estimates (Online Appendix, Tables A.6 and A.7).
} 
(age, gender, and income). The contextual (country-year) variables are: the combined Freedom House score for political rights and civil liberties; the (dis)proportionality of the electoral system, as captured by the Gallagher Index (Gallagher, 1991); the degree of institutionalization and longevity of the party system; the effective number of parties; macro-economic indicators (GDP growth, GDP per capita, unemployment, inflation, poverty rate, and Gini coefficient); and an indicator of welfare policy (total government spending on health, education and social protection, as a percentage of GDP). ${ }^{7}$ The coding and sources for all the variables are given in the Online Appendix.

\subsection{Empirical Approach}

To classify individuals into support types, we simultaneously examined the eight survey questions gauging confidence in institutions and attitudes towards democracy. This accounts for the fact that political support is a multidimensional and latent construct that cannot be accurately captured by any single indicator (Gershtenson and Plane, 2012). However, rather than following the standard practice of collapsing all items into a composite index - which would lump together and jumble the diffuse and specific components (Ulbig, 2002) - we used a supervised machine learning algorithm to sort individuals into types based on their joint responses to the eight questions while estimating the association between each item and support dimension.

Machine learning techniques have become popular in the social sciences in recent years, as they facilitate measurement, classification, and prediction in an era of increasingly larger datasets and more abundant computational resources (Grimmer, 2015). One common unsupervised machine learning tool used for classification is cluster analysis, which sorts cases into groups based on their similarity across a set of predictive features. However, while unsupervised methods may uncover interesting patterns in the data, they are entirely exploratory and can produce classifications

\footnotetext{
${ }^{7}$ Freedom House scores were reversed, giving higher values to countries with better political rights and civil liberties ratings; using Polity IV scores as an alternative did not change the the results. We also fitted models including government spending on health, education or social protection separately as indicators of welfare policy, with little effect on the results.
} 
that lack substantive relevance. To ensure that our cases (survey respondents) were classified into theoretically relevant classes, we instead applied a supervised machine learning procedure. This approach consists of two steps: (1) a training stage, where we specify what patterns to look for in a subset of the data in which predictive features (answers to the survey items) and outcomes (support types) are fully observed for all units; and (2) a test stage, where the algorithm is used to classify cases in the entire Latinobarometer dataset.

To generate the training sample required for the first stage, we selected a subset of our data consisting of 100 randomly drawn observations from each country-year. In order to learn about the underlying type of each individual in this sub-sample, we estimated a latent class model explaining the responses to the survey items as a function of two discrete latent variables representing the diffuse and specific dimensions of political support. The linear predictor $m_{i j}$ capturing the relationship between the latent variables and individual $i$ 's response to survey item $j$ is given by:

$$
m_{i j}=l_{d j}\left(c_{d i}-1\right)+l_{s j}\left(c_{s i}-1\right)
$$

where $c_{d i}$ and $c_{s i}$ are categorical variables taking values 1 (low) or 2 (high), denoting $i$ 's score on the diffuse and specific support dimensions, respectively; and the factor loadings $l_{d j}$ and $l_{s j}$ measure the strength of the relationship between $i$ 's scores on each dimension and her response to survey item $j$. Equation (1) allows - but does not force - responses to all items to be influenced by individuals' levels of both diffuse and specific support. We estimated $l_{d j}$ and $l_{s j}$ and recovered the values of $c_{d i}$ and $c_{s i}$ through Markov chain Monte Carlo (MCMC) simulations (Jackman, 2000), assigning each respondent to one of the four support types based on the sampled values of $c_{d i}$ and $c_{s i}$. More precisely, individual $i$ was classified as a "satisfied democrat" if $\left\{c_{d i}, c_{s i}\right\}=$ $\{h i g h, h i g h\}$; as a "dissatisfied democrat" when $\left\{c_{d i}, c_{s i}\right\}=\{h i g h, l o w\}$; as "antisystem" if $\left\{c_{d i}, c_{s i}\right\}=\{$ low, high $\}$; and as "alienated" if $\left\{c_{d i}, c_{s i}\right\}=\{$ low,low $\} .{ }^{8}$

\footnotetext{
${ }^{8}$ Alvarez, Levin, and Nuñez (2017) employ a similar latent class model to develop a typology of political participants. They apply their model to survey data from Argentina and use it to classify respondents into four participatory types based on reported engagement in conventional and unconventional political activities.
} 
While MCMC estimation of the latent class model is feasible in the restricted training sample, Bayesian inference becomes computationally impractical for the complete dataset containing almost 150,000 observations. Hence, for the test stage, we used a supervised machine learning algorithm to learn from the relationship between support types and survey responses in the training sample, and then applied it to classify the respondents in the cumulative Latinobarometer data (for whom only the answers to the survey questions - but not their types - are observed). We used a k-Nearest Neighbors (k-NN) algorithm to classify each respondent by "majority voting," identifying the most common type among her k-nearest hypothetical neighbors in the training sample (Hastie et al., 2009).

After this test stage, we fitted a multinomial logit model in order to examine the influence of individual and contextual variables on the probability of type assignment, simultaneously including all the micro- and macro-level determinants of political support as regressors and clustering the standard errors to accommodate arbitrary correlation in survey responses at the country-year level. ${ }^{9}$ To account for the fact that support types are estimated (rather than observed), the whole procedure (training, supervised classification and multinomial logit estimation) was repeated 100 times. Hence, the parameter estimates reported in the next section take classification uncertainty into consideration, as they were calculated by combining results across all the iterations of the learning process. ${ }^{10}$

Before discussing our results, it is important to mention two key issues related to our empirical approach. First, our strategy of combining Bayesian latent class analysis and supervised machine learning tools constitutes an important methodological contribution that improves on standard practice. When using a supervised machine learning approach, careful specification of the relationship between predictive features and outcomes in the training dataset is crucial, as it guides the learning process. By

\footnotetext{
${ }^{9}$ In principle, the estimation of the regression coefficients could be conducted as part of the classification process. This, however, can alter the substantive interpretation of the support types (e.g., Asparouhov and Muthén, 2014).

${ }^{10}$ We verified that additional (e.g., 1,000) replications yield virtually identical results.
} 
"informing" the classification algorithm with the first-stage latent class estimates, our approach allows us to construct a training dataset without resorting to commonly imposed but arbitrary restrictions on the mapping between survey items and support dimensions - e.g., assuming a priori that certain items tap into either diffuse or specific aspects only (Easton, 1975; Gershtenson and Plane, 2012). Our method ensures that respondents are classified into substantively meaningful categories without the need for such ex-ante and ad-hoc constraints, while also incorporating classification uncertainty into subsequent stages of the analysis.

Second, the number of categories of the discrete latent variables $c_{d i}$ and $c_{s i}$ in our model are dictated by our analytical framework, which - as discussed in Section 2 - distinguishes between four types of citizens depending on whether their levels of diffuse and specific support are high or low. This is a usual practice in latent class analysis when there are clear theoretical expectations regarding the nature of the groups underlying the data (Finch and Bronk, 2011). In such cases, defining the number of classes "(...) is not a statistical issue but a theoretical one that should be based on the substantive interest of the researcher" (Oberski, 2016: 180). Nonetheless, we also estimated a factor-analytic version of our model, treating diffuse and specific support as continuous latent variables without imposing any restrictions on the number of support types present in the data or on their characteristics. As we show in the Online Appendix (Figures A.2-A.5), the results reported below remain similar under this alternative measurement approach, providing empirical validation for our theoretically-derived groupings. Furthermore, we replicated our analysis using out-of-sample observations (footnote 5) to check for over-fitting, obtaining a virtually identical partition of survey respondent into support types as in our full dataset. Finally, we estimated several alternative models with different number of classes, attempting to balance parsimony and accuracy (Hallquist and Wright, 2014). As reported in Table A.2 of the Online Appendix, our preferred model outperforms these alternative specifications according to a variety of model selection criteria. Together, these robustness checks indicate that our findings are not simply an artifact of our 
empirical specification and reinforce our confidence in the validity of our conclusions.

\section{Results}

We start by examining the substantive relationship between the two dimensions of political support and the survey items used as dependent variables in our analysis. To this end, Figure 1 presents the estimated factor loadings corresponding to the latent class model (i.e. parameters $l_{d j}$ and $l_{s j}$ in equation 1 ).

Figure 1: Relationship Between Survey Items and Dimensions of Support

Diffuse Support

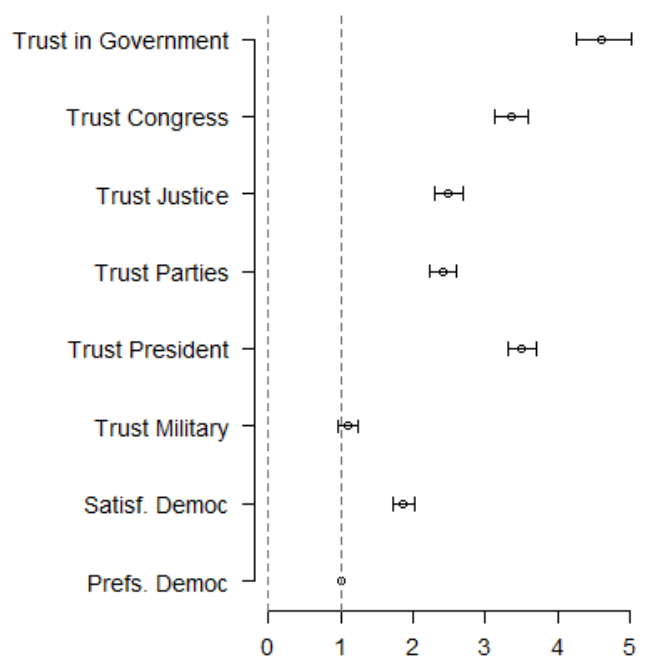

Specific Support

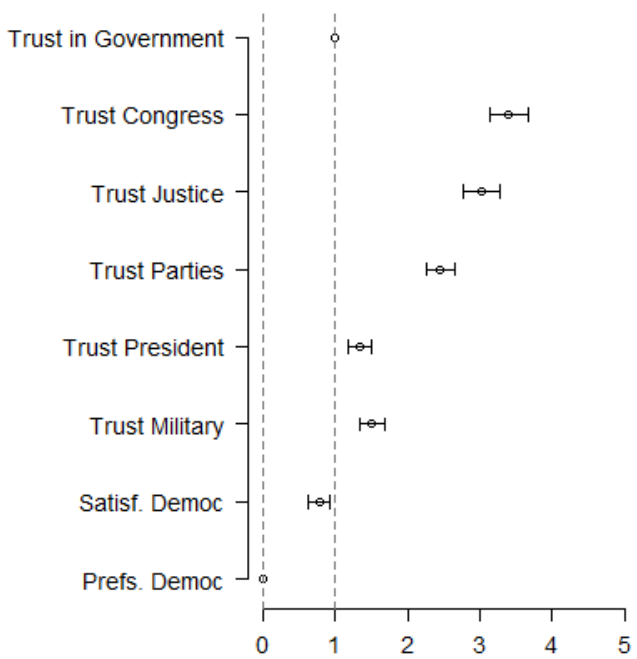

Note: The figure plots point estimates (circles) and 90\% credible intervals (horizontal lines) for the loading parameters $\left(l_{d j}, l_{s j}\right)$ of the latent class model. These parameters regulate the relationship between each survey item and the diffuse and specific scores $\left(c_{d i}, c_{s i}\right)$.

The items associated with confidence in political actors and institutions load on both the diffuse and specific scores $\left(c_{d i}\right.$ and $\left.c_{s i}\right)$. On the other hand, the items gauging satisfaction with and preference for democracy load much more heavily on the diffuse component. This highlights a difference between the two support dimensions that is consistent with Easton (1965)'s argument that diffuse support is intrinsically related to dispositions towards democratic principles and values, while specific support is 
primarily associated with evaluations of particular political actors and institutions.

To further assess whether discriminating the two support dimensions enhances the explanatory power of our analysis, we estimated an alternative specification collapsing the diffuse and specific components into a single dimension. Table A.3 in the Online Appendix compares the fit of both models based on several statistics commonly used in the mixture modeling literature (Hallquist and Wright, 2014). The results of this exercise demonstrate that our preferred specification fares better than the simpler, uni-dimensional model, indicating that accommodating the two support dimensions proposed by Easton (1965) yields a markedly improved fit and provides a better account of respondents' political attitudes than simply ignoring the distinction between diffuse and specific support ex-ante. At the same time, Figure 1 reveals that assuming a priori that certain items tap exclusively into one or the other dimension is problematic, as is the practice of collapsing all the indicators into a composite scale that ignores variations in the strength of the relationship between each indicator and support dimension.

Table 3 summarizes the responses to the different survey items among the four theoretical support types distinguished in Section 2, as well as the relative weight of each type in the Latinobarometer dataset. ${ }^{11}$ Respondents classified as satisfied democrats (alienated) display the highest (lowest) levels of confidence in political actors and institutions. For satisfied democrats, mean confidence levels in national government, Congress, the judiciary, political parties, the president and the military lie all significantly above the sample averages, while the opposite is true for alienated types. Individuals in the former group also tend to be fairly satisfied with democracy (their average score on the SWD question is 2.81 on a 4-point scale), and a vast majority of them (73\%) prefer democracy over autocracy under any circumstance. Conversely, alienated citizens are less satisfied with they way democracy works than the average survey respondent, and only $55 \%$ of them believe that democracy is always the best form of government.

Dissatisfied democrats are also strongly supportive of fundamental and functional

\footnotetext{
${ }^{11}$ Tables A.4 and A.5 in the Online Appendix detail the distribution of responses by support type.
} 
Table 3: Response Patterns across Support Types and Proportion of each Type in the Sample

\begin{tabular}{lccccc}
\hline \hline \multirow{2}{*}{ Item } & $\begin{array}{c}(1) \\
\text { Satisfied } \\
\text { democrats }\end{array}$ & $\begin{array}{c}(2) \\
\text { Dissatisfied } \\
\text { democrats }\end{array}$ & $\begin{array}{c}(3) \\
\text { Anti-system }\end{array}$ & $\begin{array}{c}(4) \\
\text { Alienated }\end{array}$ & $\begin{array}{c}(5) \\
\text { All }\end{array}$ \\
\hline Trust in Government & 3.21 & 2.86 & 1.71 & 1.28 & 2.20 \\
Trust in Congress & $(0.00)$ & $(0.00)$ & $(0.00)$ & $(0.00)$ & \\
Trust in Justice & 3.10 & 1.96 & 2.01 & 1.10 & 2.01 \\
& $(0.00)$ & $(0.00)$ & $(0.08)$ & $(0.00)$ & \\
Trust in Parties & 3.06 & 2.20 & 1.93 & 1.19 & 2.07 \\
& $(0.00)$ & $(0.00)$ & $(0.00)$ & $(0.00)$ & \\
Trust in President & 2.64 & 1.68 & 1.76 & 1.12 & 1.78 \\
& $(0.00)$ & $(0.00)$ & $(0.00)$ & $(0.00)$ & \\
Trust in Military & 3.37 & 3.04 & 1.92 & 1.44 & 2.3 \\
\multirow{2}{*}{ Satisfaction with democracy } & $(0.00)$ & $(0.00)$ & $(0.00)$ & $(0.00)$ & \\
& 3.07 & 2.40 & 2.53 & 1.78 & 2.43 \\
Preference for democracy & $(0.00)$ & $(0.00)$ & $(0.00)$ & $(0.00)$ & \\
& 2.81 & 2.48 & 2.01 & 1.80 & 2.25 \\
& $(0.00)$ & $(0.00)$ & $(0.00)$ & $(0.00)$ & \\
Proportion in the sample $(\%)$ & 0.73 & 0.72 & 0.54 & 0.55 & 0.63 \\
\hline \hline
\end{tabular}

Note: Columns (1)-(4) display average values of responses to each item among respondents assigned to different support types. Column (5) presents averages for all survey respondents. The p-values of (two-sided, paired-samples) tests for differences in item scores between each type and the whole sample are reported in parenthesis. The bottom row reports the share of each type in the sample.

aspects of democracy. Those assigned to this category are significantly more likely to be content with the workings of democracy than the average Latinobarometer respondent, and $72 \%$ of them prefer democracy over autocracy. While these individuals also exhibit above-average levels of trust in government, the president and the justice system, their confidence in parliament, political parties and the military is significantly lower than the sample average.

Lastly, anti-system types are less satisfied with the functioning of democracy than the average survey respondent, and exhibit the lowest level of support for democratic government: $46 \%$ of them prefer an autocracy or are indifferent between both regimes. These respondents also display below-average levels of trust in most political actors 
and institutions, but express relatively high confidence in the military $(2.5$ on a 4 point scale, significantly higher than the sample mean). It is not surprising for citizens with little attachment to democratic ideals to be quite supportive of the military in view of the role played by the armed forces during the dictatorships of the 1970s and 1980s and their involvement in the political life of these countries even long after the transition (Koonigs and Kruijt, 2003). Moreover, several of the "anti-system political leaders" (Hagopian, 2005: 320) that gained popularity in the region during the last decades - e.g., Gutiérrez in Ecuador, Humala in Peru, Chávez in Venezuela - were former military officers.

The bottom row of Table 3 reports the proportion of each support type in the sample. Roughly $25.5 \%$ of the respondents across all countries and years were classified as alienated, almost $29 \%$ as anti-system, $23 \%$ as satisfied democrats, and $22.5 \%$ as dissatisfied democrats. In other words, more than half of South Americans exhibit low levels of diffuse support, whereas less than a quarter of them display high scores on both the diffuse and specific dimensions. These findings are consistent with prior evidence indicating that average levels of diffuse support in South America are quite low - even among developing democracies (Hagopian, 2005).

The distribution of support types, however, varies considerably across countries. This is illustrated in Figure 2, which depicts the average size of each group for every South American country over the sample period. The proportion of satisfied democrats is highest in Uruguay (42\%), and lowest in Paraguay (18\%), Bolivia (16.5\%), Ecuador (16\%), and Peru (11\%), the four "crisis-ridden polities" (Mainwaring and Hagopian, 2005). The fraction of dissatisfied democrats, i.e., the other group of respondents with high diffuse support, is largest in Chile (31\%). The predominance of the two types of citizens with strong regime attachments in the two most robust democracies of the region is aligned with the theoretical arguments outlined in Section 2.1. At the other extreme, and also in agreement with our expectations, alienated types with low levels of diffuse and specific support are more plentiful in fragile democracies (Peru, 36\%; Ecuador, 33\%; and Paraguay, 31\%), and less abundant in 
the more solid regimes (Uruguay, 14\%; Chile, 16\%).

Figure 2: Proportion of Respondents Assigned to Each Type, by Country
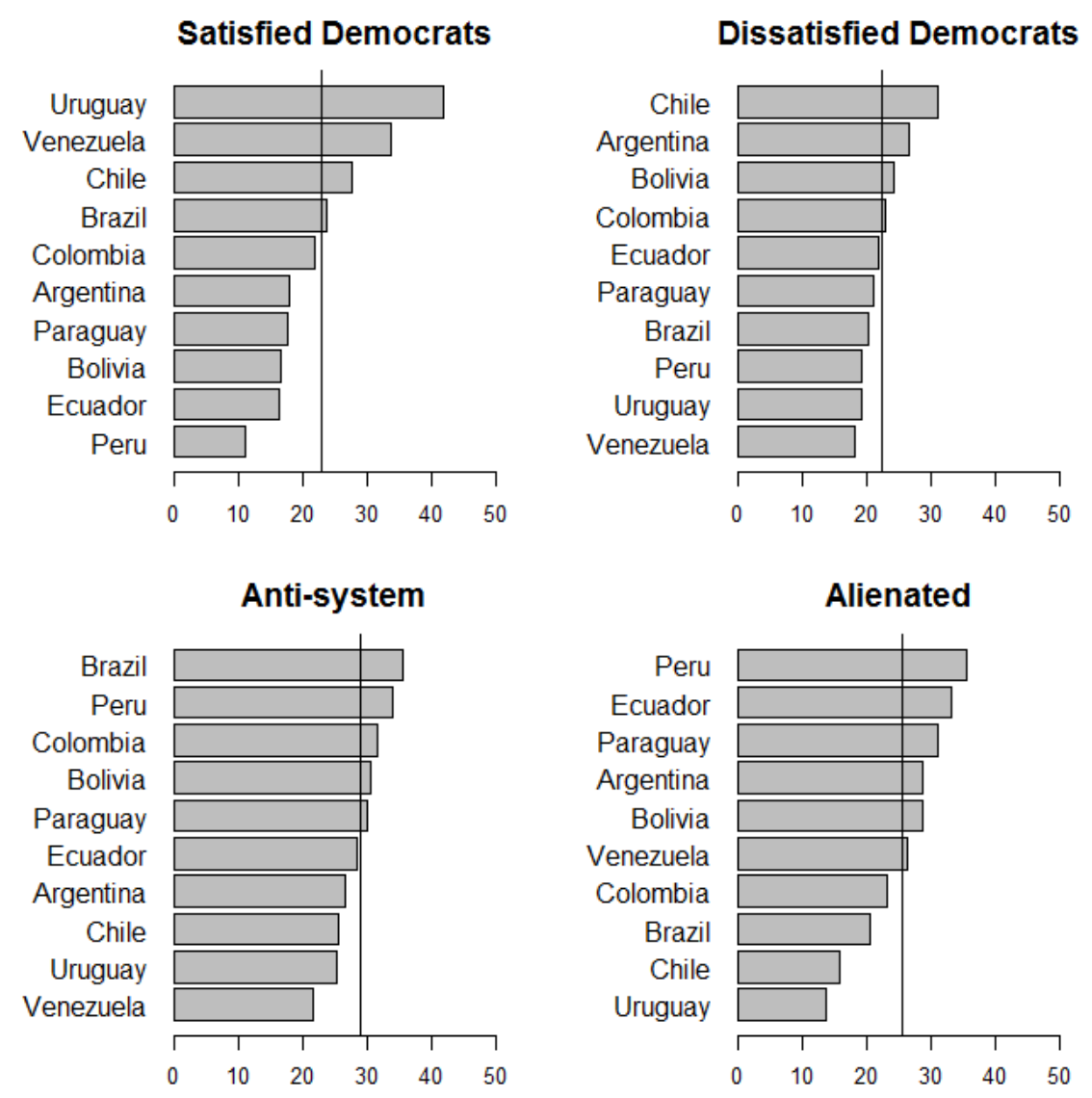

Note: Bars indicate the share of respondents allocated to the different types in each country, on average over the sample period. Vertical lines give the percentage of individuals assigned to each type across all countries and years.

Interestingly, while anti-system types are also relatively common in crisis-ridden (Peru, Bolivia, Paraguay, Ecuador) or deteriorating (Colombia) democracies, it is in Brazil where this group is more prevalent (35\% of survey participants). As we mentioned above, Mainwaring and Hagopian (2005) consider Brazil a surprising example of successful democratization in light of its deeply authoritarian political heritage. Figure 2 suggests that the nation's democratic success has not been accompanied by mass adherence to fundamental regime principles. This is in line with Weyland (2005), who contends that acceptance of democracy as the "only game in town" has 
increased among Brazilian elites but remains weak at the popular level.

By contrast Venezuela, where we anticipated a large fraction of anti-system types based on the arguments in Sections 2 and 3, has the lowest share of individuals in this category. Because most of our sample period overlaps Chavez's government, and given the erosion of democratic practices during his administration (Coppedge, 2005), we expected respondents expressing support for institutions dominated by Chavez loyalists to be ambivalent - to say the least - about democracy. However, the majority of Venezuelans who exhibit high levels of specific support also display high diffuse support. This can be seen by comparing the top- and bottom-left panels of Figure 2: the proportion of anti-system types (21\%) is considerably lower than that of satisfied democrats (34\%). While individuals in the latter group remain ultimately committed to democratic ideals, they seem willing to (temporarily) forgive democratic transgressions in exchange for - what they believe to be - competent or well functioning institutions. ${ }^{12}$ This interpretation is in accordance with Canache (2002)'s conclusions regarding the electoral support base of Chavismo.

The disparities in the relative predominance of types translate into varying levels of diffuse and specific support across polities. Figure 3 summarizes these differences, displaying the proportion of respondents classified as having high levels of diffuse (horizontal axis) and specific (vertical axis) support in each country between 1996 and 2015. The figure reveals that the two dimensions are positively correlated: countries with high (low) aggregate levels of diffuse support tend to exhibit high (low) overall scores on the specific dimension. Uruguay and Chile show above-average levels of both forms of support. The same holds true, unexpectedly but consistently with Figure 2, for Venezuela. ${ }^{13}$ On the other hand, the crisis-ridden democracies (Bolivia, Ecuador, Peru, and Paraguay) score poorly on the two dimensions. These estimates

\footnotetext{
${ }^{12}$ Alternatively, individuals in this group might actually perceive Chavismo as democratic, perhaps even as an expression of a more radical or profound kind of democracy (e.g., Ellner, 2001). However, this view is difficult to square with Batista, Seligson, and Zechmeister (2013)'s finding that the vast majority of committed democrats in Venezuela favor checks and balances.

${ }^{13}$ This result is also consistent with previous findings based on different methods and data sources (e.g., Batista, Seligson, and Zechmeister, 2013).
} 
Figure 3: Relationship between Diffuse and Specific Support

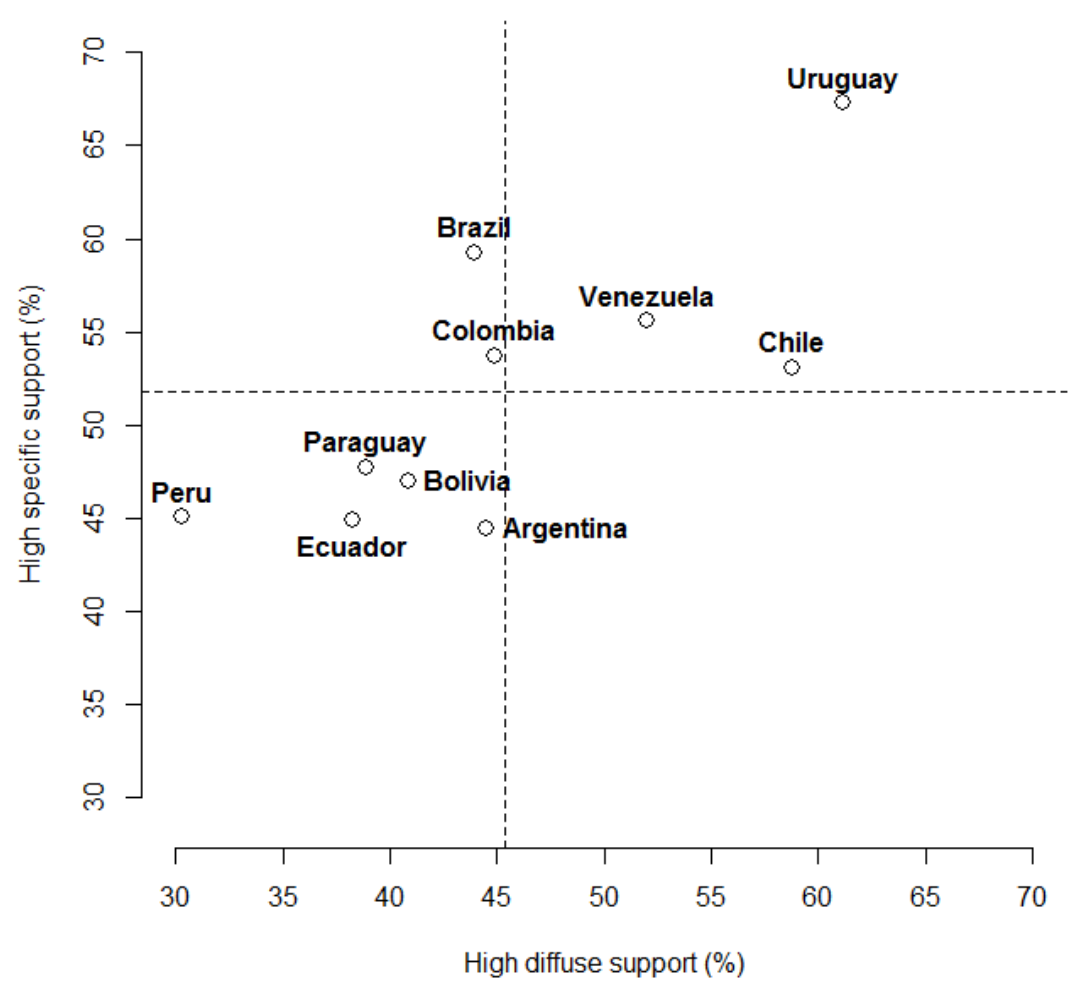

Note: Circles indicate the share of respondents with high levels of diffuse and specific support between 1996 and 2015. Dashed lines give cross-country averages throughout the sample period.

lend credence to our argument that the diffuse and specific components may be more tightly linked than has been typically assumed; Figure A.6 in the Online Appendix shows that this close connection is also verified for most countries over time.

Figures 2 and 3 highlight relevant differences in the varieties and dimensions of support across South American nations. The impact of institutional, performancerelated and socio-demographic factors on these differences is examined in Figures 4 and 5. As seen in Figure 4, four institutional characteristics exert a systematic influence on the relative prevalence of the different support types: the extent to which civil rights and political liberties are safeguarded in practice, the degree of institutionalization of the party system, the effective number of parties (ENP), and 
the disproportionality of the electoral system.

Figure 4: Marginal Effects of Contextual Factors on Type Assignment

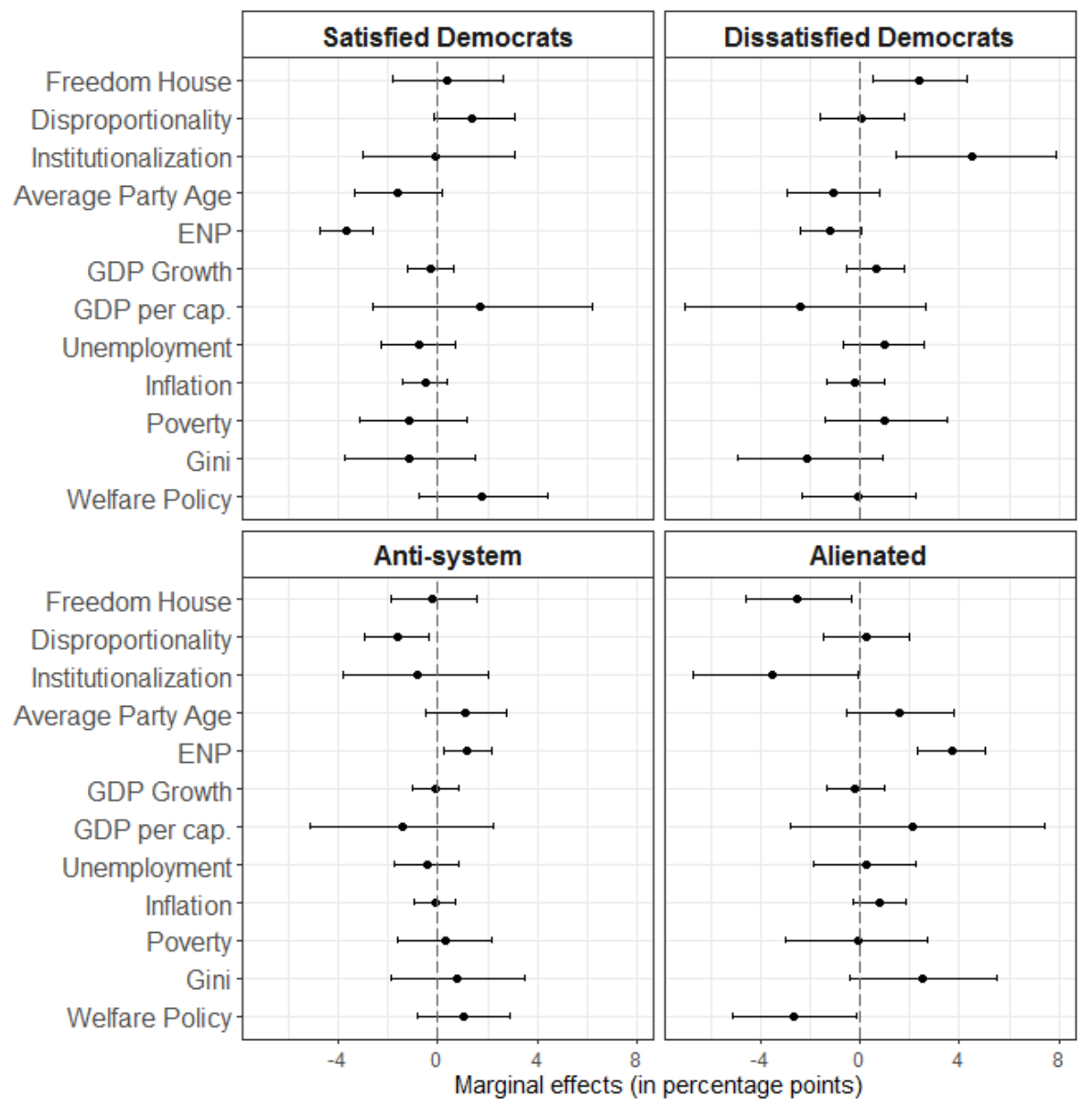

Note: Circles represent the expected change in the probability of assignment to each type associated with a change in the covariates. Horizontal lines give $90 \%$ confidence intervals.

Keeping everything else fixed, each point increase in Freedom House's (inverted) combined score for political rights and civil liberties is associated with a 2.4 percentage point increase in the probability that the typical respondent is classified as a dissatisfied democrat, and a 2.6 point decrease in her probability of belonging to the alienated class. This variable has no significant impact on the proportion of either satisfied democrats or anti-system types. Hence, a more effective protection of civil and political rights - taken as a proxy for the level of democratization or democratic quality of a polity (Booth and Seligson, 2009; Norris, 1999) - affects regime's 
perceived legitimacy among South Americans disenchanted with political actors and institutions. When the overall quality of democracy is (comparatively) high, even individuals who distrust political actors and state institutions adhere to elementary democratic tenets. In contrast, at lower levels of democratization, mistrust of political decision-makers is more easily conjoined with low diffuse support.

A similar conclusion holds regarding the institutionalization of the party system: a higher degree of institutionalization is associated with a lower share of alienated types and a higher fraction of dissatisfied democrats. This is in consonance with Levitsky and Cameron (2003)'s thesis that more institutionalized party systems provide citizens with opportunities to channel their dissatisfaction with incumbents and government bodies through or within the political establishment. Instead, when parties are weakly linked to the citizenry and unable to represent its interests or voice its demands, politically dissatisfied citizens tend to "withdraw" from politics. The degree of institutionalization of the party system has also a negative impact on the percentage of anti-system types on average, although - contrary to our expectations - this marginal effect is statistically indistinguishable from zero.

Each additional "viable" party, in turn, is accompanied by a one percentage point increase in the fraction anti-system types and a 3.1 point increase in the share of alienated respondents. Concomitantly, the proportions of satisfied and dissatisfied democrats decline by 3.1 and 1.0 points, respectively. Altogether, the proportion of respondents classified as having high diffuse support drops by 9.1 percentage points for every additional viable party in the system, while the fraction of participants with high levels of specific support diminishes by 8.6 points. These findings conform to the notion that effective policy-making becomes more challenging as the number of parties with a realistic chance of obtaining political representation grows (e.g., Weil, 1989). In South America, this not only undercuts support for the politicians and institutions in charge of implementing policy, but also for democratic government.

As for the disproportionality of the electoral system, we expected - drawing on Freitag and Bühlmann (2009) and Norris (1999) - a more equitable representation 
of political interests in the decision-making process to be positively correlated with diffuse and specific support. This expectation is not borne out by the data. Each standard deviation increase in the Gallagher Index is correlated with a 0.5 percentage point reduction in the fraction of anti-system types, which is matched by a rise in the proportion of satisfied democrats. That is, electoral disproportionality induces a near perfect trade-off between the two types with high specific support; the overall levels of diffuse and specific support remain essentially unchanged. This result, together with the estimated effects for ENP, suggests that South Americans tend to have an instrumental view of representative democracy: while the combination of fewer parties and more disproportional electoral rules limits representativeness, it may enhance government effectiveness and potentially improve policy outcomes - which, our analysis indicates, play a key role in public assessments of democracy in the region. ${ }^{14}$

Related to this point, Figure 4 shows that welfare policies have a considerable impact on the varieties of political support: the share of alienated respondents drops by 0.9 percentage points with each percentage increase in governments' social expenditure (on health, education and social protection). Objective measures of economic performance, on the other hand, do not significantly affect the distribution of support types. Nevertheless, macro-economic outcomes have an indirect influence on political support through their impact on citizens' subjective economic evaluations, as illustrated in Figure 5.

Respondents who thought that their country's economy or their own financial circumstances had improved a little over the previous year were significantly more likely to be classified as satisfied or dissatisfied democrats than those who thought that the economic situation of their nation or of their household had worsened during the same period. Socio-tropic (i.e. other-regarding) and pocketbook (i.e. self-regarding) optimism also reduced the probability of assignment to the anti-system or alienated

\footnotetext{
${ }^{14}$ We also fitted specifications including an interaction between ENP and the Gallagher Index. As discussed in Section 3, the combination of strongly proportional systems and a large number of parties may render policy-making especially difficult. While - consistent with Figure 4 - disproportionality tends to mitigate the negative impact of ENP on support, the interaction is not significant.
} 
Figure 5: Marginal Effects of Individual Variables on Type Assignment

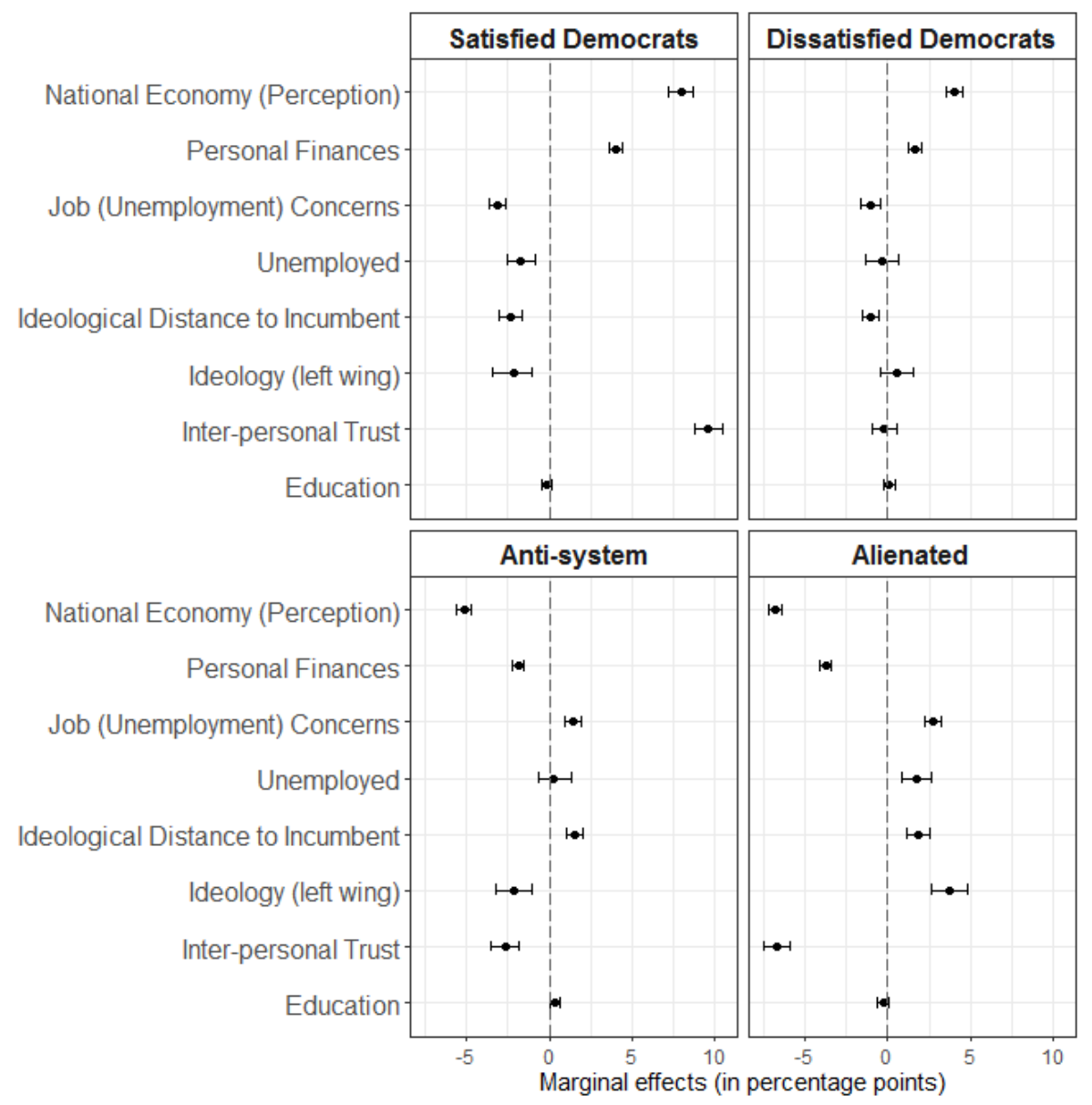

Note: Circles represent the expected change in the probability of assignment to each type associated with a change in the covariates. Horizontal lines give $90 \%$ confidence intervals.

categories. Similarly, participants who were worried about losing their job were 3.2 percentage points less likely to fall in the category of satisfied democrats than those not at all concerned about job security, and one point less likely to be classified as dissatisfied democrats. At the same time, concerns about job security increased the probability of holding anti-system views or becoming alienated by 1.4 and 2.8 points, respectively. The joint impact of economic judgments is quite sizable, and - in line with the findings in Katz and Levin (2016) - influences not only public assessments of political decision-makers but, more importantly, opinions about democracy. Holding all other variables at their mean sample values, a respondent who believed that na- 
tional and personal economic conditions had improved over the previous 12 months and who thought her job was secure was 44.6 percentage points more likely to have a high level of specific support, and a whopping 59.7 points more likely to exhibit high diffuse support, than someone with negative economic perceptions.

Individuals' political beliefs are also relevant predictors of type assignment. Each increase in the average respondent's ideological distance to the ruling party reduces the likelihood that she is classified as a convinced - either satisfied or dissatisfied democrat while simultaneously raising her probability of holding anti-system views or becoming alienated from politics. Thus, whereas research in advanced democracies has shown that being politically close to the incumbent government renders citizens more supportive of the administration and of representative institutions (Listhaug, 1995), ideological distance between mass and elites seems to have more fundamental implications in South America, as it can undermine faith in core democratic principles. Additionally, moving to the left of the ideological spectrum reduces the probability of being assigned to the group of satisfied democrats by 2.2 percentage points, raising the likelihood of being classified as alienated by 3.8 points. Our results are partially consistent with Seligson (2007)'s conclusion that Latin American leftists express little support for democracy: $56 \%$ of them show indeed low levels of diffuse support in our sample. On the other hand, the estimates in Figure 5 indicate that, keeping all other variables constant, a left-winger with low regime support is 2.2 percentage points less likely to embrace anti-system values than someone with equally low regard for democratic forms of government but placed to the right of the ideological scale.

Inter-personal trust is another significant individual-level driver of political support. Respondents who believed that "one can trust most people" were 9.6 percentage points more likely to be classified as satisfied democrats than those who manifested that "one can never be too careful when dealing with others." Higher inter-personal trust was also significantly correlated with decreases in the probability of being tagged as anti-system (-2.7 percentage points) and alienated (-6.7 points).

The relationship between education and political support in South America is re- 
vealing. Previous studies have found that, in well-established regimes, more educated individuals tend to be more supportive of democratic government but also more critical of its functioning in practice (e.g., Dalton, 2005; Magalhães, 2013). Our estimates, however, uncover no systematic differences in the degree of either diffuse or specific support between more educated respondents - those with a university degree - and participants with average - secondary - education levels. In this respect, the results for our sample countries resembles those for other recently democratized - e.g., Asian (Rose, Shin, and Munro, 1999) - nations. As Rose, Shin, and Munro (1999) note, this is to some extent a reassuring finding, as it suggests that regime support in these (comparatively) novel democracies is not confined to the academic or intellectual elite. That said, education does have some influence on South Americans with low diffuse support: conditional on having little faith in democracy, individuals with a college degree are 0.3 percentage points more likely to be classified as anti-system than those with secondary education. In other words, when disappointed with democratic practices and procedures, highly educated respondents are somewhat more prone to turn to anti-establishment political options than the rest.

The role of economic perceptions and social policy indicators in determining citizens' type assignment suggests that the relative weight of the different varieties of political support might have fluctuated over the sample period. As discussed in Section 2.1, institutional and socio-demographic characteristics may contribute to explain cross-national differences in support (as corroborated in Figures 4 and 5), but these factors tend to be rather stable. Performance-related measures, on the other hand, can be quite volatile, and thus more likely to account for the dynamics of support types. Figure 6, which tracks the evolution of each type's share in the Andean (Bolivia, Ecuador, Colombia, Peru, Venezuela) and Southern Cone (Argentina, Brazil, Chile, Paraguay and Uruguay) countries, shows that there were indeed some noticeable shifts in the distribution of support types over time.

The share of alienated types increased by 37 percentage points in the Southern Cone and by 68 points in the Andean countries between 2000 and 2003, as the ef- 
Figure 6: Regional Dynamics of Political Support
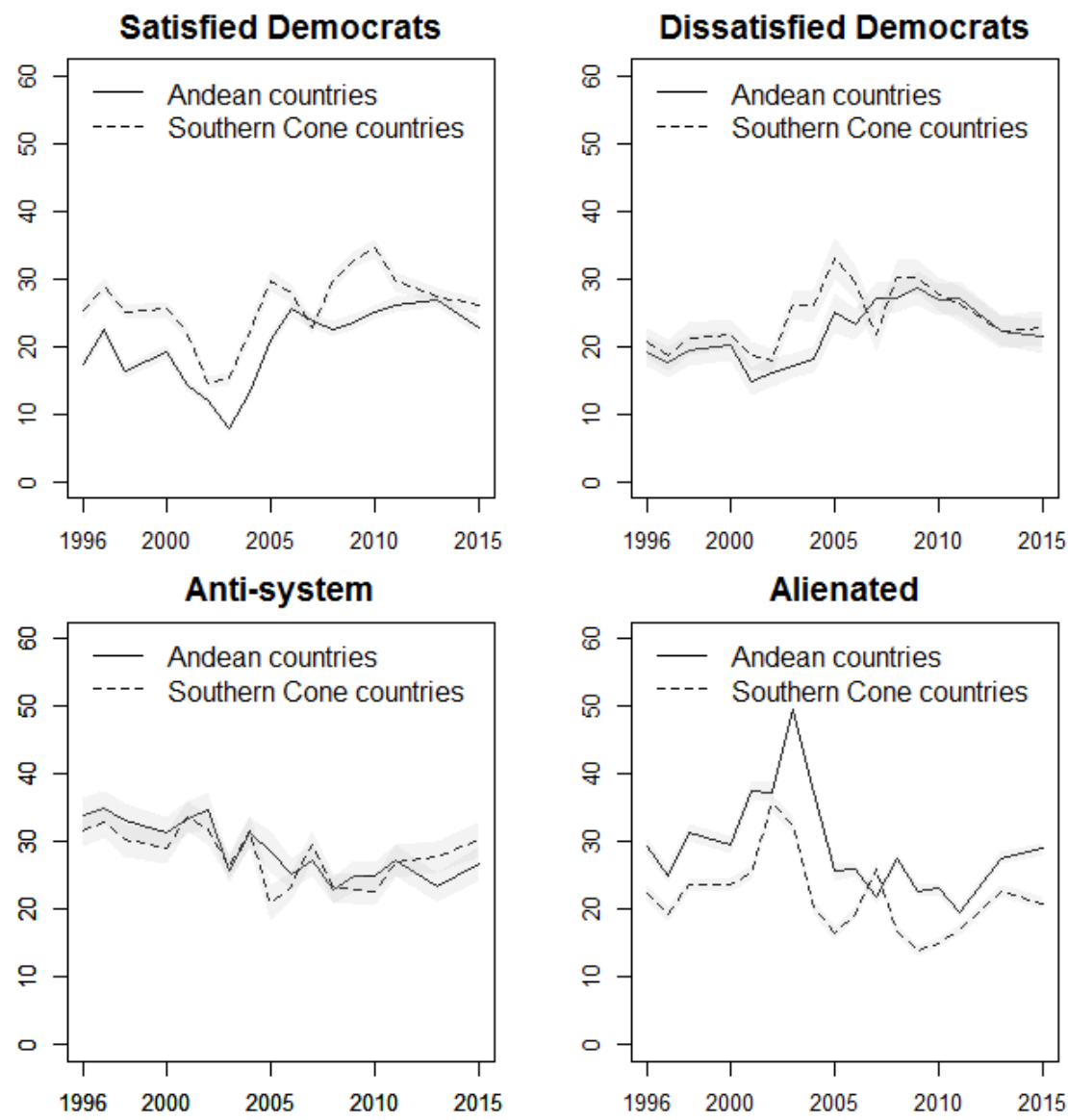

Note: Solid (dashed) lines represent average shares of each support type in Andean (Southern Cone) countries between 1996 and 2015; shaded areas give $90 \%$ confidence intervals.

fect of the international (Asian and Russian) financial crises of the late 1990s rippled across South America. As seen in Figure A.1 in the Online Appendix, these years brought about a pronounced downturn in all South American nations. Moreover, as demonstrated by Gautam (2015), these crises were accompanied by substantial reductions in aggregate social expenditure throughout the region, as governments faced stringent budget restrictions. The impact of the recession was short-lived, though: the proportion of alienated respondents in the Andes and the Southern Cone dropped drastically the following year - when the whole region began a period of recovery and returned to its pre-crisis levels already in 2005. Although the relative size of this 
group rose again after 2009, following the global financial meltdown, this shift was much more moderate, as the economic repercussions of this event were comparatively mild for South America (Figure A.1). The curve representing the share of satisfied democrats is almost the mirror image of its counterpart for alienated respondents. In contrast, the fraction of dissatisfied democrats and anti-system respondents remained more stable throughout the period. Figures A.8 and A.9 in the Online Appendix show that country-level dynamics were generally consistent with these (sub-)regional patterns.

The evidence in Figure 6 thus confirms that performance variables - economic outcomes, through their influence on citizens' retrospective evaluations, and social policy outputs - were key determinants of the evolution of diffuse and specific support over the sample period. The share of respondents with high diffuse (specific) support dropped by 10.4 (15.0) percentage points between 2000 and 2003, but recovered in full less than two years later. The two dimensions responded in tandem to the economic developments of the early 2000s, further substantiating our claim that adherence to democratic principles and norms in the region is closely linked to evaluations of political actors and of the outputs produced by the political system.

\section{Conclusion}

Drawing on Easton (1965)'s theoretical framework, this paper develops an analytical typology to characterize differences in citizens' levels of diffuse and specific support, applying a novel empirical strategy that combines Bayesian inference, machine learning methods and regression models to assess the impact of individual and contextual variables on the prevalence and evolution of different support types. Our approach allows studying the dynamic relationship between the two support dimensions and the interplay between their determinants, filling a relevant gap in the literature.

Our study of South American survey data covering the last two decades reveals that more than half of the respondents exhibit little attachment to fundamental and functional aspects of democracy, while less than a quarter score high on both the 
diffuse and specific dimension of political support. The prevalence of different citizen types varies across countries and over time, reflecting institutional, performance and socio-demographic factors. The dynamics of the two support dimensions are closely linked, and are especially sensitive to changes in economic conditions influencing individuals' retrospective judgments and social policy outputs. Contrary to prior research on industrialized nations, our estimates indicate that negative economic shocks not only undermine support for particular government actors but, more worryingly, also fuel disenchantment with democracy. On a positive note, both support dimensions bounce back rather quickly in periods of economic recovery.

Although our analysis has clear regional and temporal specificity, South American polities share common features with other young democracies not only in Latin America, but also in Africa, Asia and Central-Eastern Europe. In many of these countries, the process of democratic consolidation proved challenging, legal and political institutions remain under-developed, and the quality of democratic governance is still precarious (Hagopian, 2005; Rose, Shin, and Munro, 1999). Moreover, as in South America, democratic transitions in Eastern Europe and some African nations occurred in tandem with market-oriented reforms that produced widespread economic dislocations and heightened political stress for the new regimes (Mishler and Rose, 1999; Webster and Adler, 1999). As a result, like South America's anti-system and alienated types, a sizable fraction of the citizenry in several post-transitional societies is highly skeptical about democracy. For instance, more than a third of the citizens in the former communist bloc were nostalgic of the old regime a decade after the fall of the Iron Curtain, and a hefty proportion of them continue to express reservations about the new regime (Fuchs and Roller, 2006; Segovia, 2008). Likewise, Doorenspleet (2012) shows that almost a quarter of Afrobarometer respondents expresses little attachment to democratic forms of government. Under these circumstances, the risk persists that, faced with economic crises or external shocks, some of these nations may revert to their authoritarian legacy (Norris, 1999: 2).

Our findings are somewhat encouraging in this respect, as they suggest that even 
when diffuse support may be quite volatile in emerging democracies, it can be ultimately resistant to fluctuations in system performance. And, as discussed in Section 3 , there is reason to believe that diffuse support should be even more resilient in other embryonic democracies where perceived regime legitimacy is higher than in South America. Although generalizing lessons from context-specific studies is always difficult, our theoretical framework and empirical strategy could be easily applied to different periods and polities outside South America, allowing to assess the robustness of our conclusions in alternative settings. The growing availability of long public opinion time-series data for other new democracies renders this a natural extension of our study. Such extension would also enable testing the impact of other factors - e.g., the distinction between presidential and parliamentary systems - that exhibit little or no variation in our sample but may be nonetheless important for explaining the level and/or dynamics of diffuse and specific support from a broader comparative perspective. More generally, contrasting trends among a larger set of nations and distinguishing common structural patterns from region-specific trajectories would help better understand the mechanisms governing the motion of the two dimensions and their interactions, complementing and expanding the literature in this area. We leave a thorough examination of these issues for future work.

\section{References}

Alvarez, R.M., Levin, I., Nuñez, L. 2017. The Four Faces of Political Participation in Argentina: Using Latent Class Analysis To Study Political Behavior. Forthcoming, J. Polit.

Asparouhov, T., Muthén, B. 2014. Auxiliary Variables in Mixture Modeling: ThreeStep Approaches Using Mplus. Struc. Eq. Model. 21, 329-341.

Bargsted, M., Somma, N.M., Castillo, J.C. 2017. Political Trust in Latin America. In: Zmerli, S., van der Meer, T. (Eds.), Handbook on Political Trust. Elgar, Northampton, pp. 395-417.

Batista, F., Seligson, M., Zechmeister, E. 2013. AmericasBarometer: Topical Brief, Insights Series N. ITB002 (March 11, 2013). 
Bejarano, A.M., Pizarro, E. 2005. From "Restricted" to "Besieged": The Changing Nature of the Limits to Democracy in Colombia. In: Hagopian, F., Mainwaring, S. (Eds.), The Third Wave of Democratization in Latin America: Advances and Setbacks. Cambridge University Press, New York, pp. 235-260.

Booth, J.A., Seligson, M.A. 2009. The Legitimacy Puzzle in Latin America: Democracy and Political Support in Eight Nations. Cambridge University Press, New York.

Canache, D. 2002. From Bullets to Ballots: The Emergence of Popular Support for Hugo Chávez. Lat. Am. Pol. and Soc. 44, 69-90.

Coppedge, M. 2005. Explaining Democratic Deterioration in Venezuela through Nested Inference. In: Hagopian, F., Mainwaring, S. (Eds.), The Third Wave of Democratization in Latin America: Advances and Setbacks. Cambridge University Press, New York, pp. 289-316.

Dalton, R.J. 1999. Political Support in Advanced Industrial Democracies. In: Norris, P. (Ed.), Critical Citizens: Global Support for Democratic Governance. Oxford University Press, New York, pp. 57-77.

Dalton, R.J. 2005. The Social Transformation of Trust in Government. Int. Rev. Sociol. 15, 133-154.

Doorenspleet, R. 2012. Critical Citizens, Democratic Support and Satisfaction in African Democracies. Int. Pol. Sci. Rev. 33, 279-300.

Easton, D. 1965. A Systems Analysis of Political Life. Wiley, New York.

Easton, D. 1975. A Re-Assessment of the Concept of Political Support. Brit. J. Pol. Sci. 5, 435-467.

Ellner, S. 2011. Venezuela's Social-Based Democratic Model: Innovations and Limitations. J. Lat. Am. Stud. 43, 421-449.

Finch, W.H., Bronk, K.C. 2011. Conducting Confirmatory Latent Class Analysis Using Mplus. Struc. Eq. Model. 18, 132-151.

Freitag, M., Bühlmann, M. 2009. Crafting Trust - The Role of Political Institutions in a Comparative Perspective. Comp. Pol. Stud. 42, 1537-1566.

Fuchs, D., Roller, E. 2006. Learned Democracy? Support of Democracy in Central and Eastern Europe. Int. J. Sociol. 36, 70-96.

Gallagher, M. 1991. Proportionality, Disproportionality and Electoral Systems. Elec. Stud. 10, 33-51. 
Gautam, R. 2015. Banking Crises and Social Policy: the Case of Latin America and the Caribbean. J. Int. and Comp. Soc. Policy. 31, 209-233.

Gershtenson, J., Plane, D. 2012. An Alternative Measure of Political Trust: Reconciling Theory and Practice. In: Aldrich, J.H., McGraw, K.M. (Eds.), Improving Public Opinion Surveys: Interdisciplinary Innovation and the American National Election Studies. Princeton University Press, Princeton, pp. 117-36.

Gilley, B. 2009. The Right to Rule: How States Win and Lose Legitimacy. Columbia University Press, New York.

Grimmer, J. 2015. We Are All Social Scientists Now: How Big Data, Machine Learning, and Causal Inference Work Together. PS: Pol. Sci. \& Pol. 48, 80-83.

Hagopian, F. 2005. Government Performance, Political Representation, and Public Perceptions of Contemporary Democracy in Latin America. In: Hagopian, F., Mainwaring, S. (Eds.), The Third Wave of Democratization in Latin America: Advances and Setbacks. Cambridge University Press, New York, pp. 319-362.

Hallquist, M.N., Wright, A.G. 2014. Mixture Modeling Methods for the Assessment of Normal and Abnormal Personality I: Cross-sectional Models. J. Pers. Assess. 96, $256-268$.

Hastie, T., Tibshirani, T., Friedman, J., Franklin, J. 2009. The Elements of Statistical Learning: Data mining, Inference and Prediction. Springer, New York.

Holmberg, S. 1999. Down and Down We Go: Political Trust in Sweden. In: Norris, P. (Ed.), Critical Citizens: Global Support for Democratic Governance. Oxford University Press, New York, pp. 103-122.

Jackman, S. 2000. Estimation and Inference Are Missing Data Problems: Unifying Social Science Statistics via Bayesian Simulation. Pol. An. 8, 307-332.

Jones. M. 2012. The Diversity of Latin American Democracy. World Polit. Rev. (March 20, 2012), 9-14.

Katz, G., Levin, I. 2016. The Dynamics of Political Support in Emerging Democracies: Evidence from a Natural Disaster in Peru. Int. J. Pub. Op. Res. 28, 173-195.

Klingemann, H.D. 1999. Mapping Political Support in the 1990s: A Global Analysis. In P. Norris (Ed.), Critical Citizens: Global Support for Democratic Governance. Oxford University Press, New York, pp. 31-56.

Koonings, K., Kruijt, D. 2003. Latin American Political Armies in the Twenty-First Century. Bull. Lat. Am. Res. 22, 371-384. 
Levitsky, S. 2005. Argentina: Democratic Survival amidst Economic Failure. In: Hagopian, F., Mainwaring, S. (Eds.), The Third Wave of Democratization in Latin America: Advances and Setbacks. Cambridge University Press, New York, pp. 6389.

Levitsky, S., Cameron, M.A. 2003. Democracy Without Parties? Political Parties and Regime Change in Fujimori's Peru. Lat. Am. Pol. and Soc. 45, 1-33.

Lewis-Beck, M.S., Stegmaier, M. 2000. Economic Determinants of Electoral Outcomes. An. Rev. Poli. Sci. 3, 113-122.

Linde, J. 2004. Doubting Democrats? A Comparative Analysis of Support for Democracy in Central and Eastern Europe. Unpublished PhD Dissertation, Örebro University.

Linde, J., Ekman, J. 2003. Satisfaction with Democracy: A Note on a Frequently Used Indicator in Comparative Politics. Europ. J. Pol. Res. 42, 391-408.

Listhaug, O. 1995. The Dynamics of Trust in Politicians. In: Klingemann, H.D., Fuchs, D. (Eds.), Citizens and the State. Oxford University Press, Oxford, pp. 261-297.

Magalhães, P. 2013. Government Effectiveness and Support for Democracy. Europ. J. Pol. Res. 53, 77-97.

Mainwaring, S. 2006. The Crisis of Democratic Representation in the Andes. J. Democ. $17,13-27$.

Mainwaring, S., Hagopian, F. 2005. Introduction. In: Hagopian, F., Mainwaring, S. (Eds.), The Third Wave of Democratization in Latin America: Advances and Setbacks. Cambridge University Press, New York, pp. 1-13.

Mishler, W., Rose, R. 1999. Five Years after the Fall: Trajectories of Support for Democracy in Post-Communist Europe. In P. Norris (Ed.), Critical Citizens: Global Support for Democratic Governance. Oxford University Press, New York, pp. 78-99.

Mishler, W., Rose R. 2005. What Are the Political Consequences of Trust? A Test of Cultural and Institutional Theories in Russia. Comp. Pol. Stud. 38, 1050-1078.

Norris, P. 1999. Critical Citizens: Global Support for Democratic Governance. Oxford University Press, New York.

Oberski, D. 2016. Adv. Data Anal. Classif. 10, 171-182.

Payne, J.M., Zovatto, D., Mateo, M. 2007. Democracies in Development - Politics and Reform in Latin America. Inter-American Development Bank, Washington, D.C. 
Rose, R., Shin, D.C., Munro, N. 1999. Tensions Between the Democratic Ideal and Reality: South Korea. In: Norris, P. (Ed.), Critical Citizens: Global Support for Democratic Governance. Oxford University Press, New York, pp. 146-165.

Rothstein, B., Stolle, D. 2008. The State and Social Capital: An Institutional Theory of Generalized Trust. Comp. Pol. 40, 441-59.

Segovia, C. 2008. Political Trust in Latin America. Unpublished PhD Dissertation, University of Michigan.

Seligson, M.A. 2007. The Rise of Populism and the Left in Latin America. J. Democ. $18,81-95$.

Torcal, M., Montero, J.R. 2006. Political Disaffection in Comparative Perspective. In: Torcal, M., Montero, J.R. (Eds.), Political Disaffection in Contemporary Democracies: Social Capital, Institutions and Politics. Routledge, New York, pp. 3-20.

Ulbig, S.G. 2002. Policies, Processes, and People: Sources of Support for Government? Soc. Sci. Quart. 83, 789-809.

Webster, E., Adler, G. 1999. Towards a Class Compromise in South Africa's "Double Transition": Bargained Liberalization and the Consolidation of Democracy. Pol. \& Soc. 27, 347-385.

Weil, F.D. 1989. The Sources and Structure of Legitimation in Western Democracies. Am. Soc. Rev. 54, 682-706.

Weitz-Shapiro, R. 2008. The Local Connection: Local Government Performance and Satisfaction With Democracy in Argentina. Comp. Pol. Stud. 41, 285-308.

Weyland, K. 2005. The Growing Sustainability of Brazil's Low-Quality Democracy. In: Hagopian, F., Mainwaring, S. (Eds.), The Third Wave of Democratization in Latin America: Advances and Setbacks. Cambridge University Press, New York, pp. 90-129.

Zmerli, S., Newton, K., Montero, J.R. 2007. Trust in People, Confidence in Political Institutions, and Satisfaction with Democracy. In: van Deth, J.W., Montero, J.R., Westholm, A. (Eds.), Citizenship and Involvement among the Populations of European Democracies. A Comparative Analysis. Routledge, London, pp. 35-65. 


\section{Online Appendix}

This Appendix accompanying the paper "Varieties of Political Support in Emerging Democracies: A Cross-National Analysis" includes information about data sources and coding and additional estimation results. Specifically, Section A presents additional socio-economic and performance indicators for South American countries, supplementing the discussion in Section 3 of the paper. Section B presents the definition, coding and sources for the dependent and independent variables included in our empirical analysis. Sections C includes several figures (C.1) and tables (C.2) reporting additional estimation results that supplement the information presented in the empirical section (Section 5) of the text. Finally, Section D lists additional sources consulted for the elaboration of this Appendix. 


\section{A. Additional socio-economic and performance in- dicators for South American countries}

Table A.1: Socio-economic characteristics of South American countries, 2015

\begin{tabular}{|c|c|c|c|c|c|c|}
\hline Country & $\begin{array}{c}\text { GDP per } \\
\text { per capita }^{a}\end{array}$ & $\begin{array}{c}\text { Growth, GDP } \\
\text { per capita }(\%)^{b}\end{array}$ & $\begin{array}{l}\text { Poverty } \\
\qquad(\%)^{c}\end{array}$ & $\begin{array}{l}\text { Inequality } \\
\text { (Gini) }\end{array}$ & $\begin{array}{l}\text { Illiteracy } \\
\qquad(\%)^{d}\end{array}$ & $\begin{array}{c}\text { Infant } \\
\text { Mortality }^{e}\end{array}$ \\
\hline Argentina & 10,571 & 1.8 & 28.7 & 0.40 & 1.9 & 11.1 \\
\hline Bolivia & 2,390 & 2.3 & 38.6 & 0.47 & 4.9 & 30.6 \\
\hline Brazil & 11,164 & 1.4 & 10.0 & 0.52 & 7.4 & 14.6 \\
\hline Chile & 14,547 & 2.7 & 6.3 & 0.48 & 3.4 & 7.0 \\
\hline Colombia & 7,448 & 2.1 & 27.8 & 0.52 & 5.4 & 13.6 \\
\hline Ecuador & 5,367 & 1.7 & 23.3 & 0.48 & 5.5 & 18.4 \\
\hline Paraguay & 3,826 & 1.4 & 22.2 & 0.49 & 4.5 & 17.5 \\
\hline Peru & 5,935 & 3.3 & 21.8 & 0.45 & 5.6 & 13.1 \\
\hline Uruguay & 13,949 & 2.9 & 9.7 & 0.39 & 1.5 & 8.7 \\
\hline Venezuela & 7,926 & 0.3 & 33.1 & 0.40 & 4.6 & 12.9 \\
\hline \multicolumn{7}{|c|}{$\begin{array}{l}\text { Sources: Economic Commission for Latin America and the Caribbean (2017), Inter- } \\
\text { American Development Bank (2017), World Bank (2017), and national } \\
\text { statistics offices. } \\
\text { Notes: } \\
\quad \text { In } 2010 \text { US dollars; }{ }^{b} \text { Annual average, } 1996-2015 ;{ }^{c} \% \text { of people below the poverty } \\
\text { line; }{ }^{d} \text { As } \% \text { of people aged } 15 \text { and older; }{ }^{e} \text { Per } 1,000 \text { births. }\end{array}$} \\
\hline
\end{tabular}


Figure A.1: Economic Growth in South America, 1996 - 2015
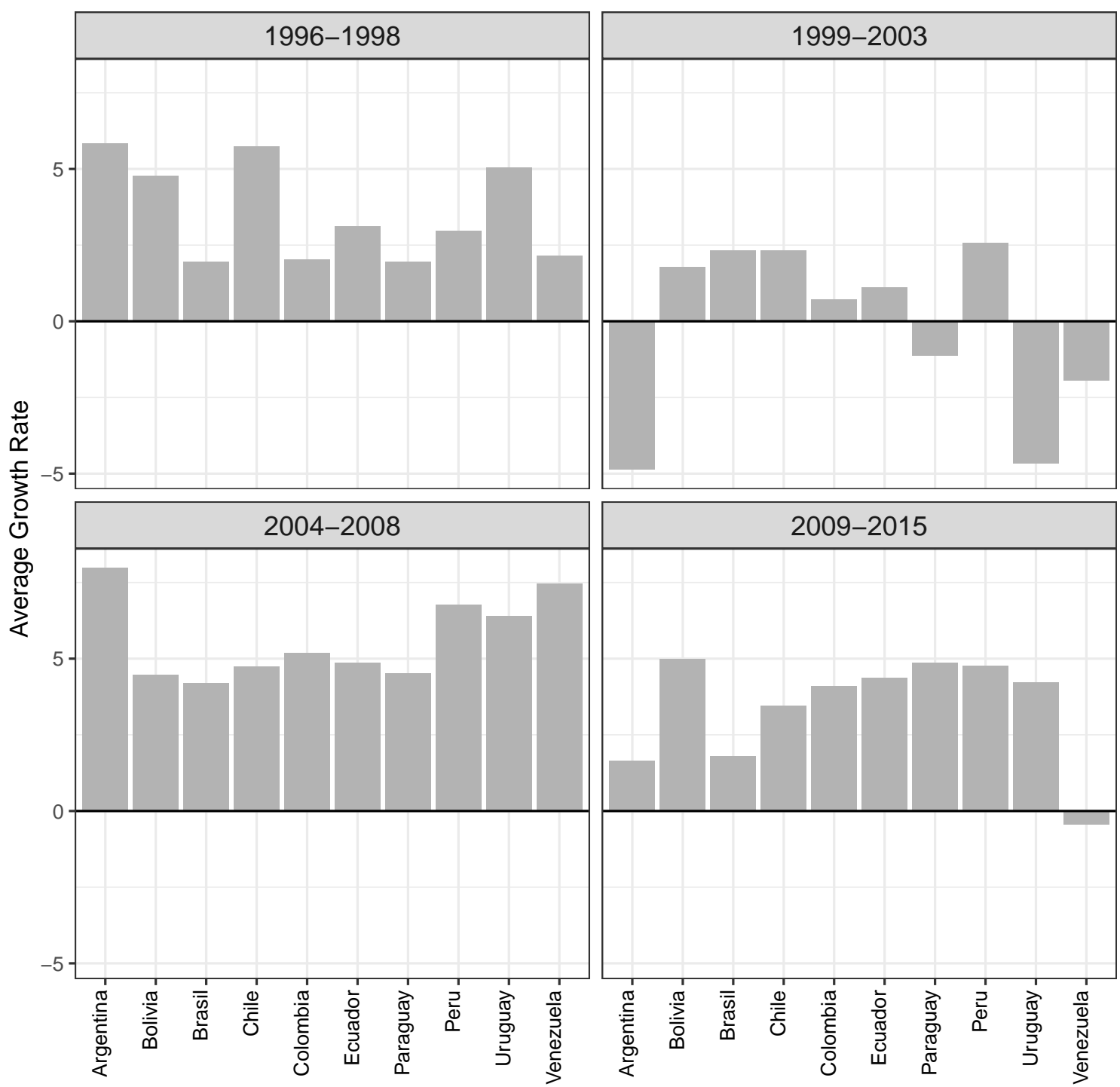

Note: The figure plots the average growth rates of the ten South American countries over the (almost) two decades covered in our analysis. The period between 1996 and 1998 includes the years from the beginning of our study up until the effects of the Asian and Russian financial crises rippled across the region (Roberts, 2008). The effects of these crises were mainly felt between 1999 and 2003. After that, South America went through one of the most buoyant periods in its recent history (Córdova and Seligson, 2009), fostered by improved terms of trade, favorable access to credit, high commodity prices and a strong world economy. The global credit and financial meltdown of 2008 brought this "panglossian period" (Izquierdo and Talvi, 2009: 5) to an end. 


\section{B. Coding and sources for the variables included in the analysis}

Dependent variables - Source: Latinobarometer Surveys, 1996 - 2015.

Trust in political actors and institutions: Question wording (coding between parentheses): "Please look at this card and tell me how much trust you have in each of the following groups/institutions. Would you say you have (4) a lot, (3) some, (2) a little, or (4) no trust?" Institutions considered in the analysis: the National Government, the President, the National Congress, the Political Parties, the Judiciary, and the Military.

Satisfaction with democracy: Question wording: "In general, would you say you are very satisfied, quite satisfied, not very satisfied or not at all satisfied with the working of the democracy in (country)?" Response alternatives (coding between parentheses): (4) "very satisfied," (3) "quite satisfied," (2) "not very satisfied," and (3) "not at all satisfied."

Preference for democracy: Question wording: "With which of the following statements do you agree most?" Response alternatives (coding between parentheses): (a) "Democracy is preferable to any other kind of government;" (b) "Under some circumstances, an authoritarian government can be preferable to a democratic one;" (c) "For people like me, it doesn't matter whether we have a democratic or non-democratic regime." Responses recoded as 1 if option (a) was selected, and 0 otherwise. 


\section{Explanatory variables}

Individual-level covariates - Source: Latinobarometer Surveys, 1996 - 2015.

National Economy (Perception): Question wording: "Do you consider the country's present economic situation to be better, a little better, the same, a little worse or much worse than 12 months ago?" Response alternatives (coding between parentheses): (5) "much better," (4) "a little better," (3) "the same," (2) "a little worse," (1) "much worse."

Personal Finances: Question wording: "Do you consider your economic situation and that of your family to be much better, a little better, about the same, a little worse or much worse than 12 months ago?" Response alternatives (coding between parentheses): (5) "much better," (4) "a little better," (3) "the same," (2) "a little worse," (1) "much worse."

Job (Unemployment) Concerns: Question wording: "How concerned would you say you are that you will be left without work or unemployed during the next 12 months? Or don't you have a job?" Response alternatives (coding between parentheses): (4) "very concerned," (3) "concerned," (2) "a little concerned," (1) "not at all concerned."

Unemployed (Employment Status): 1 if respondent is "temporarily out of work," 0 otherwise.

Ideological Distance to Incumbent: Absolute value of the difference between respondents' ideology (self-placement on the 0-10 left-right scale) and the ideology of the incumbent party. Party ideologies were computed from Baker (2016), and rescaled to the 0-10 range to match individuals' self-placement. 
Ideology (left wing): Based on survey participant's self-placement on the left-right (0-10) ideological scale. Responses were recoded as 1 if self-placement lower than 6 (i.e. left of ideology spectrum), 0 otherwise.

Inter-personal Trust: Question wording: "Generally speaking, would you say that you can trust most people, or that you can never be too careful when dealing with others?" Response alternatives (coding between parentheses): (1) "one can trust most people," (0) "one can never be too careful when dealing with others."

Education: 17-point scale. Categories: (1) without education, (2) one year of formal education, (3) two years, (4) three years, (5) four years, (6) five years, (7) six years, (8) seven years, (9) eight years, (10) nine years, (11) ten years, (12) eleven years, (13) twelve years (complete secondary education), (14) incomplete technical training, (15) complete technical training, (16) incomplete university, (17) completed university.

\section{(Additional controls)}

Age, in years.

Female: 1 if the respondent is female, 0 otherwise.

Income: Income proxy based on the number of durable goods owned by respondents' family and access to basic public services: car, home, computer, phone at home, refrigerator, TV, washing machine, hot water, running water, sewer. Ranges from 0 to 10 .

Media Use: Sum of number of days spent: (a) watching political news on public 
$\mathrm{TV}$; (b) reading political news in a newspaper; and (c) listening to political news on the radio, divided by 3 .

Contextual (country-year) predictors.

Freedom House: Mean combined score for political rights and civil liberties. The scores for political rights and civil liberties were first reversed so as to give higher values to country-years with better political rights a civil liberties ratings. As an alternative, we used the POLITY Combined Polity Score, with no substantive change in the results reported in the main text. Sources: Freedom House (2017) and Polity IV Project (2016).

Disproportionality: Measured using the Gallagher (least squares) Index, which reflects an electoral system's relative disproportionality between votes received by the competing parties and seats allotted in a legislature (Gallagher, 1991). Higher values of the Gallagher Index indicate a greater disparity between votes and seats, i.e., that elections have produced more disproportional outcomes. A Gallagher score of 0 would indicate that the election produced perfectly proportional outcomes. Sources: Gallagher (2016) and Gandrud (2015), updated for the latest elections in each South American country using vote returns obtained from the Political Database of the Americas (http://pdba.georgetown.edu/), Adam Carr's Election Archive (http://psephos.adam-carr.net/), and national election authorities.

Party System Institutionalization: Measured using the Party institutionalization index (v2xps_part) built by the Varieties of Democracy Project. This index captures several attributes of the political parties in each country-year, including the level and depth of organization, links to civil society, cadres of party activists, party supporters within the electorate, coherence of party platforms and ideologies, party-line voting 
among representatives within the legislature. Higher scores on the index indicate a more institutionalized party system. Source: V-Dem, Varieties of Democracy (2017).

Average Party Age: Average age of parties in the system. Source: Cesi, Keefer, and Scartascini (2016).

Effective Number of Parties (ENP): Computed for each election using Laakso and Taagepera (1979)'s formula. Source: Vote returns for each country-year obtained from the Political Database of the Americas (http://pdba.georgetown.edu/), Adam Carr's Election Archive (http://psephos.adam-carr.net/), and national election authorities.

GDP Growth: Rate of growth of the total annual Gross Domestic Product (GDP) at constant (2010) prices in dollars. Source: Economic Commission for Latin American and the Caribbean (2017).

GDP per capita: Total annual Gross Domestic Product (GDP) per capita at constant (2010) prices in dollars. Source: Economic Commission for Latin American and the Caribbean (2017).

Unemployment: Unemployment rate, both sexes. Source: Economic Commission for Latin American and the Caribbean (2017). For Bolivia, the information was complemented with data from the Ministry of Economics and Finance (2011).

Inflation: Variations in the consumer prices index general level, annual average. Source: Economic Commission for Latin American and the Caribbean (2017).

Poverty: Percentage of the population living below the national poverty line. 
Source: Economic Commission for Latin American and the Caribbean (2017). For Argentina, official statistics were supplemented with data from Di Santi (2016) and the Catholic University of Argentina (2017).

Gini coefficient: Sources: Economic Commission for Latin American and the Caribbean (2017), Inter-American Development Bank (2017) and World Bank (2017), complemented with data from Amarante and Vigorito (2006), Arguello, Lemus and Sánchez (2007), the Catholic University of Argentina (2017), the Ministry of Popular Planning of Venezuela (2015), the National Statistics Institute of Uruguay (2016), and SUMATE (2016).

Welfare Policy: Sum of government spending on health, education and social protection, as a percentage of the annual Gross Domestic Product (GDP). For robustness, we also fitted models including government spending on each of these items (health, education or social protection) separately as indicators of welfare policy, without affecting the results reported in Section 5 of the paper. Source: Economic Commission for Latin American and the Caribbean (2017). 


\section{Additional Estimation Results}

\section{C.1 Supplementary Figures}

Figures A.2-A.4 below allow assessing the appropriateness of assuming that the underlying measures of diffuse and specific support can be represented as taking discrete values, comparing the results produced by a latent class model with two binary latent classes vis-à-vis those produced by an analogous factor analytical model placing respondents along two continuous latent dimensions. Figure A.5 reports the (survey) item factor loadings estimated from this factor analytical model.

Results found using the discrete and continuous latent approaches were qualitatively very similar, even though the latter approach imposes no restrictions on either the number of support types present in the data or on their characteristics. As shown in Figure A.2, individuals estimated to have high values of diffuse/specific support by the factor analytical model were systematically classified into the corresponding high-level categories by the latent class model. Likewise, Figures A.3 and A.4 show that individuals classified as having high levels of diffuse/specific support by the latent class model were consistently assigned higher values of diffuse/specific support along the respective continuous dimensions. This suggests that the latent class model behaved as if the algorithm was able to identify a natural cutoff along underlying attitudes, splitting the data in a non-arbitrary and data-driven manner. These results therefore provide empirical validation for our theoretically-derived groupings.

The remaining figures (A.6 - A.9) supplement the results reported in Section 5

of the manuscript. In particular, Figure A.6 plots country-level correlations between diffuse and specific support, complementing the information presented in Figure 3 of the paper. Figure A.7, in turn, plots the expected change in the probabilities of type assignment associated with a change in additional socio-demographic controls (age, gender, income, media use), supplementing the information summarized in Figure 5 of the main text. Finally, Figures A.8 and A.9 summarize the evolution of the 
four types of political support in each of the Andean and Southern Cone countries considered in our analysis, complementing the information in Figure 6 of the paper.

Figure A.2: Relationship between continuous traits and discrete classifications
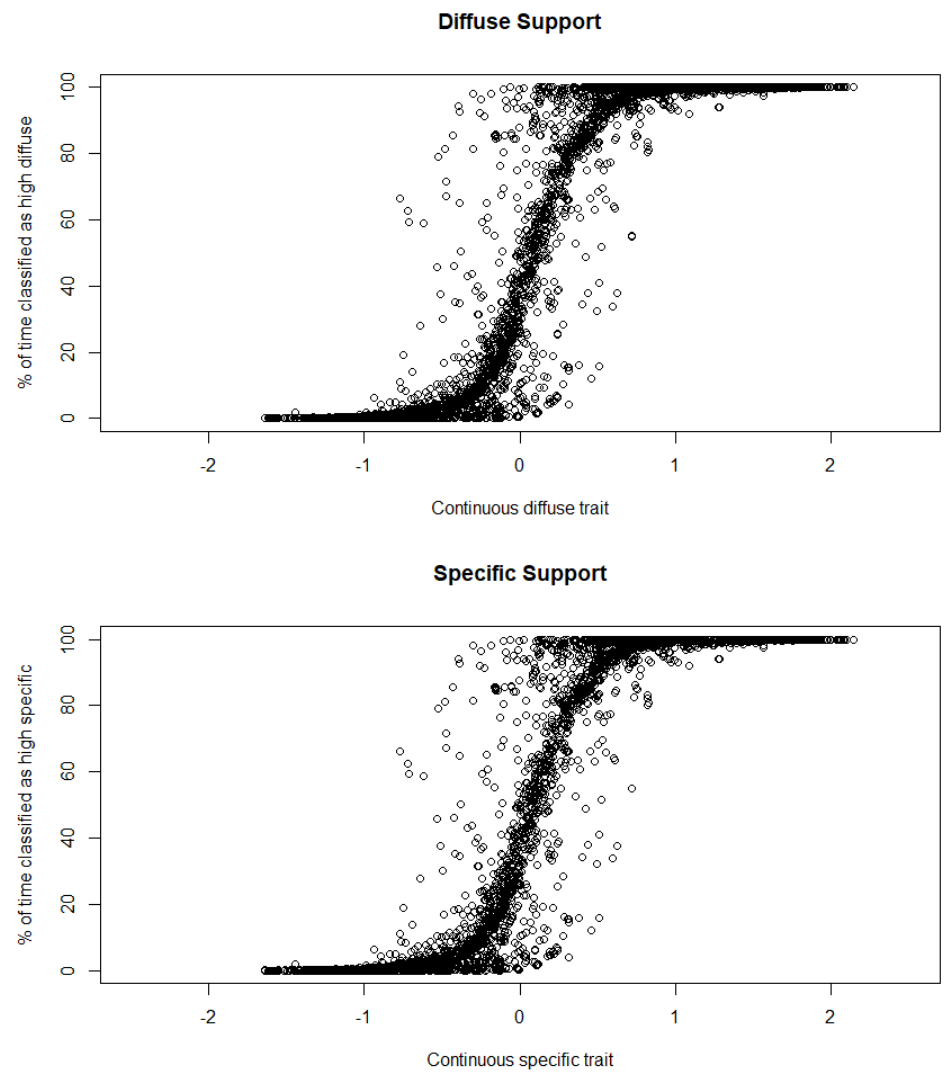

Note: The plot depicts the relationship between the estimated diffuse and specific continuous latent traits for each respondent in our sample, and the percentage of the time that each respondent was classified as having a high diffuse (upper panel) and high specific (lower panel) support by our latent class model. 
Figure A.3: Distribution of Diffuse Trait Among Individuals Classified as Having High/Low Scores on the Diffuse Dimension of our Latent Class Model

High Diffuse Support

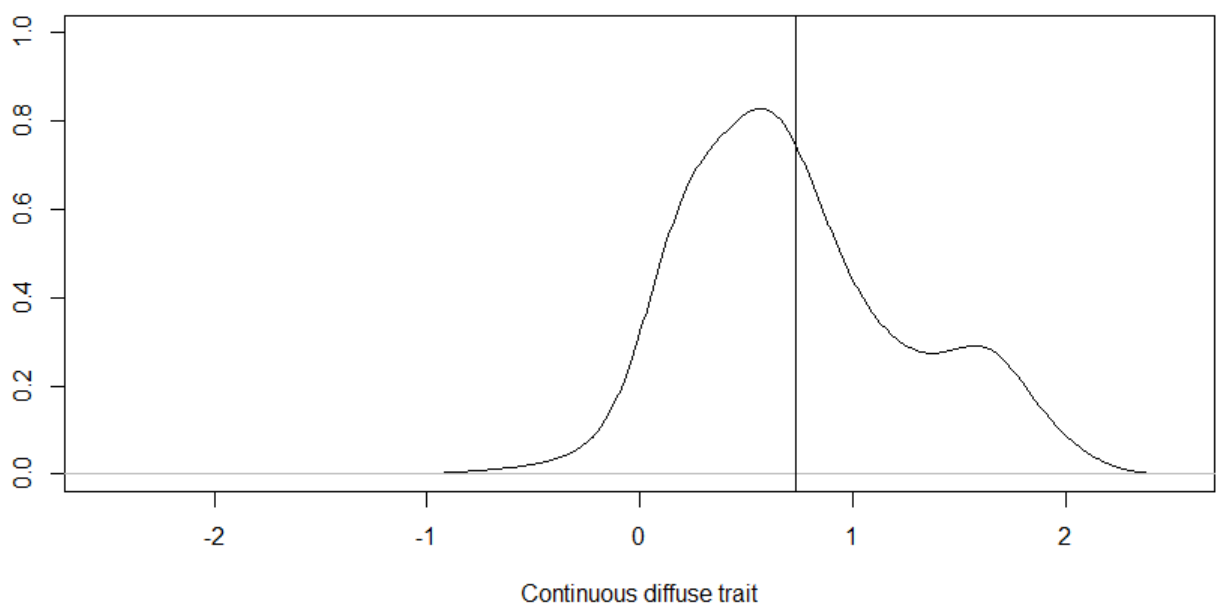

Low Diffuse Support

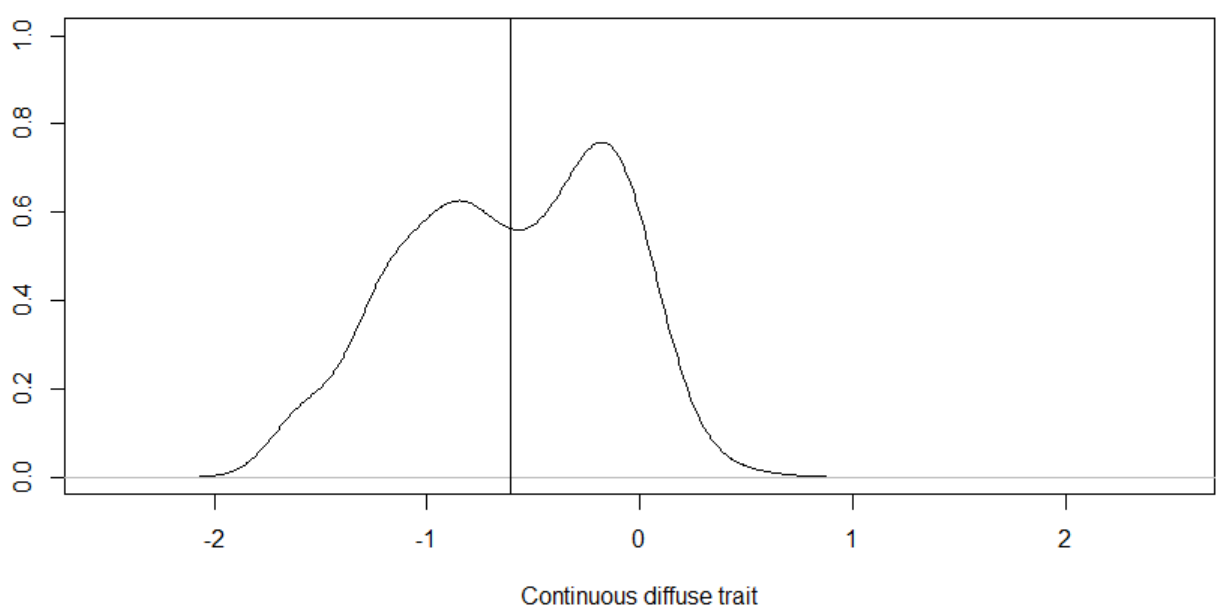

Note: The plot depicts the distribution of continuous diffuse latent traits (estimated using a factor analytical model without imposing restrictions on the number or characteristics of support types) for individuals classified by our latent class model as having high (upper pane) and low (lower panel) scores on the diffuse dimension. Vertical lines indicate the average value of the diffuse latent trait calculated over all individuals with high/low scores on the discrete diffuse dimension. 
Figure A.4: Distribution of Specific Trait Among Individuals Classified as Having High/Low Scores on the Specific Dimension of our Latent Class Model

\section{High Specific Support}

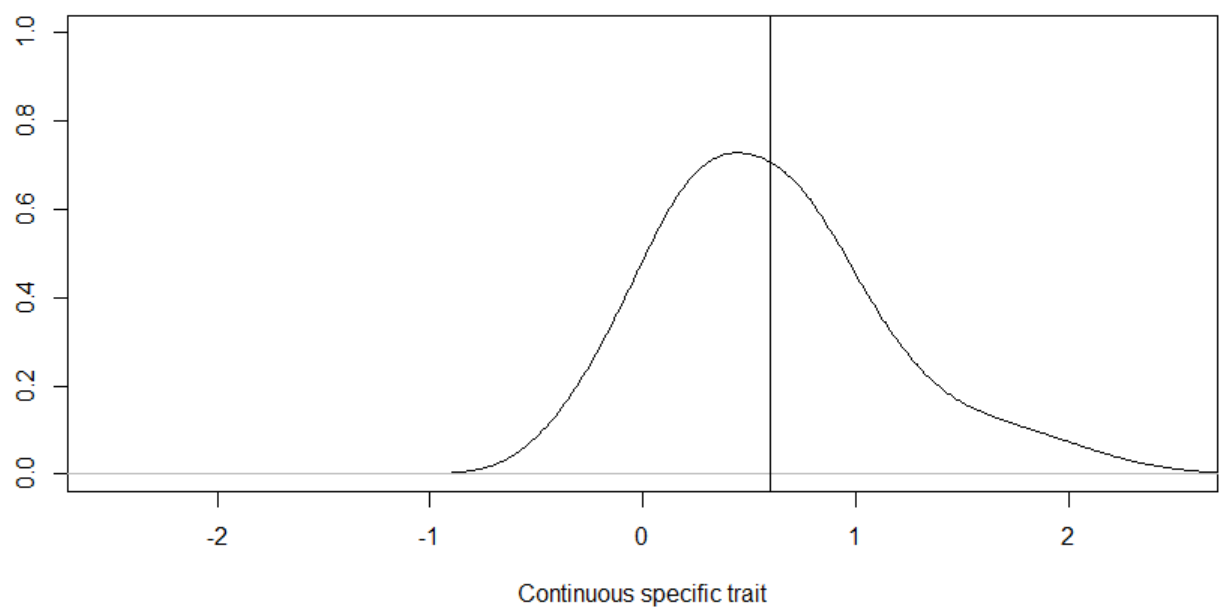

Low Specific Support

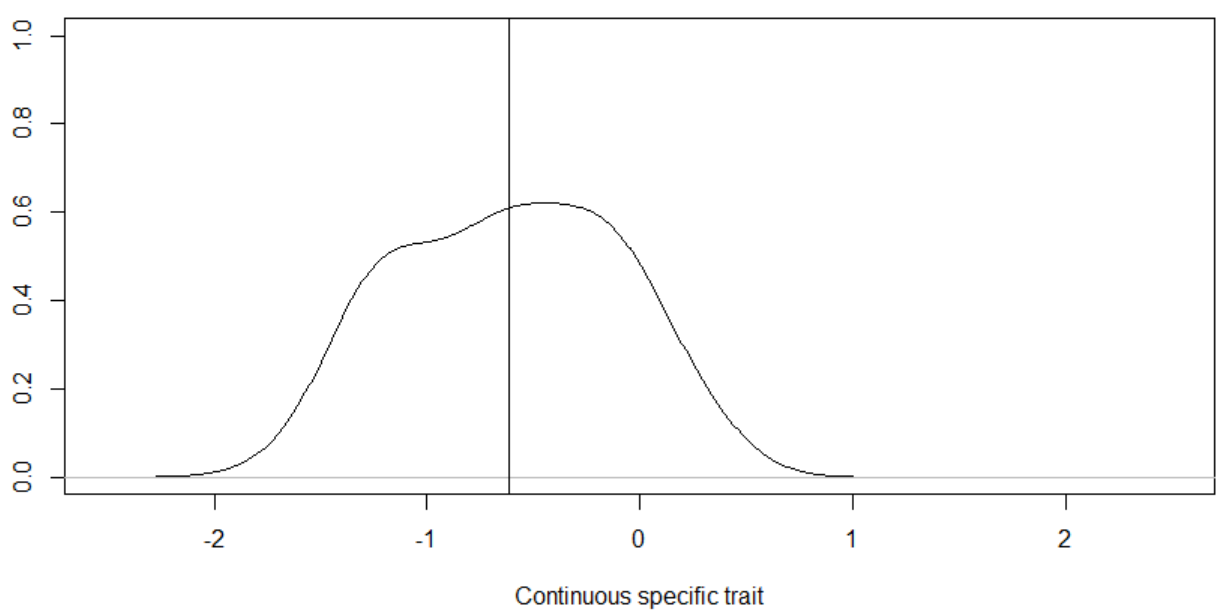

Note: The plot depicts the distribution of continuous specific latent traits (estimated using a factor analytical model without imposing restrictions on the number or characteristics of support types) for individuals classified by our latent class model as having high (upper panel) and low (lower panel) scores on the specific dimension. Vertical lines indicate the average value of the specific latent trait calculated over all individuals with high/low scores on the discrete specific dimension. 
Figure A.5: Item Loadings of our Factor Analytical Model
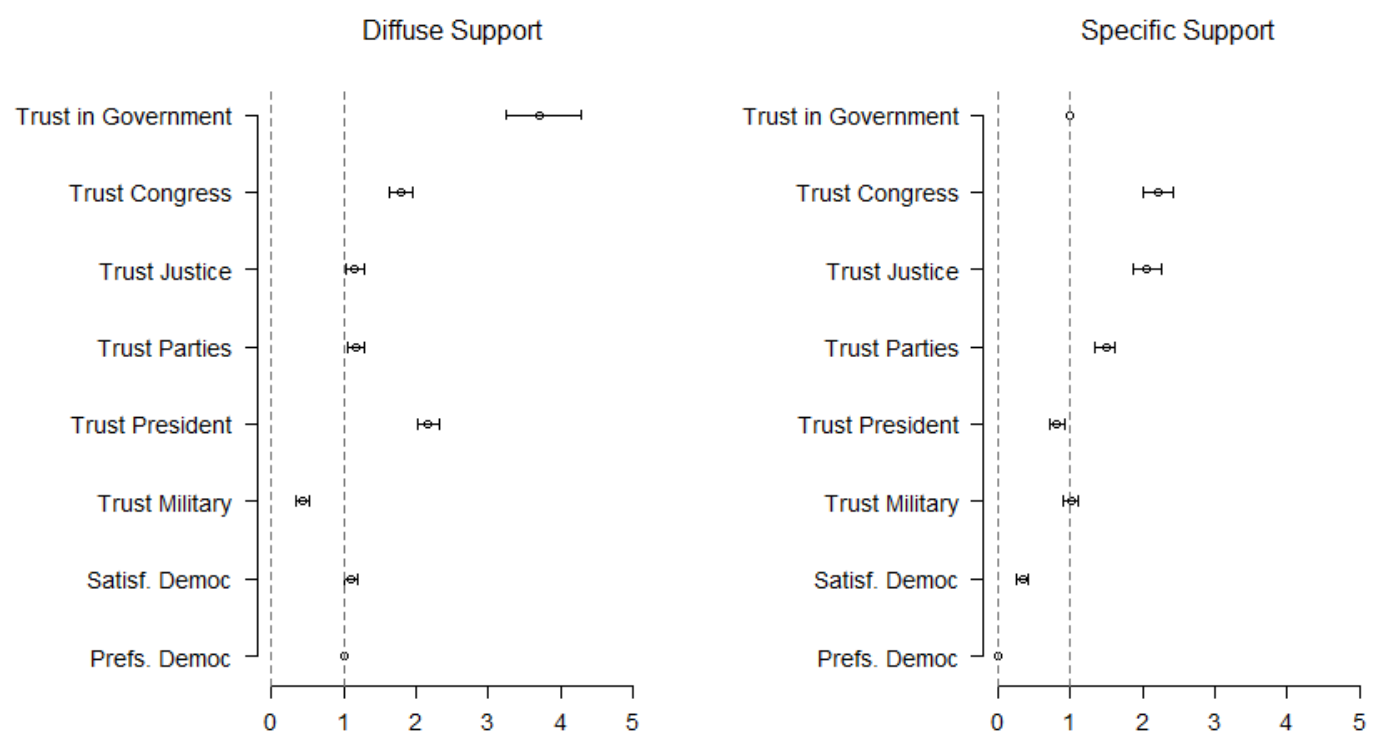

Note: The plot reports point estimates (circles) and 90\% credible intervals (horizontal lines) for the loading parameters of our factor analytical model. These parameters regulate the relationship between each survey item (see labels along vertical axis) and the diffuse (left panel) and specific (right panel) continuous latent traits. 
Figure A.6: Diffuse and Specific Support by Country
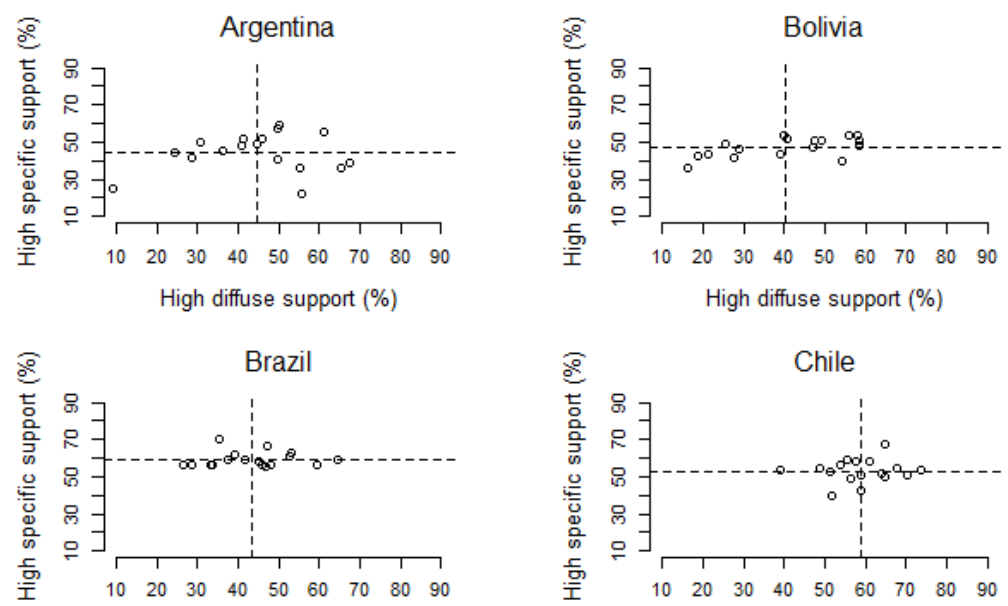

High diffuse support (\%)
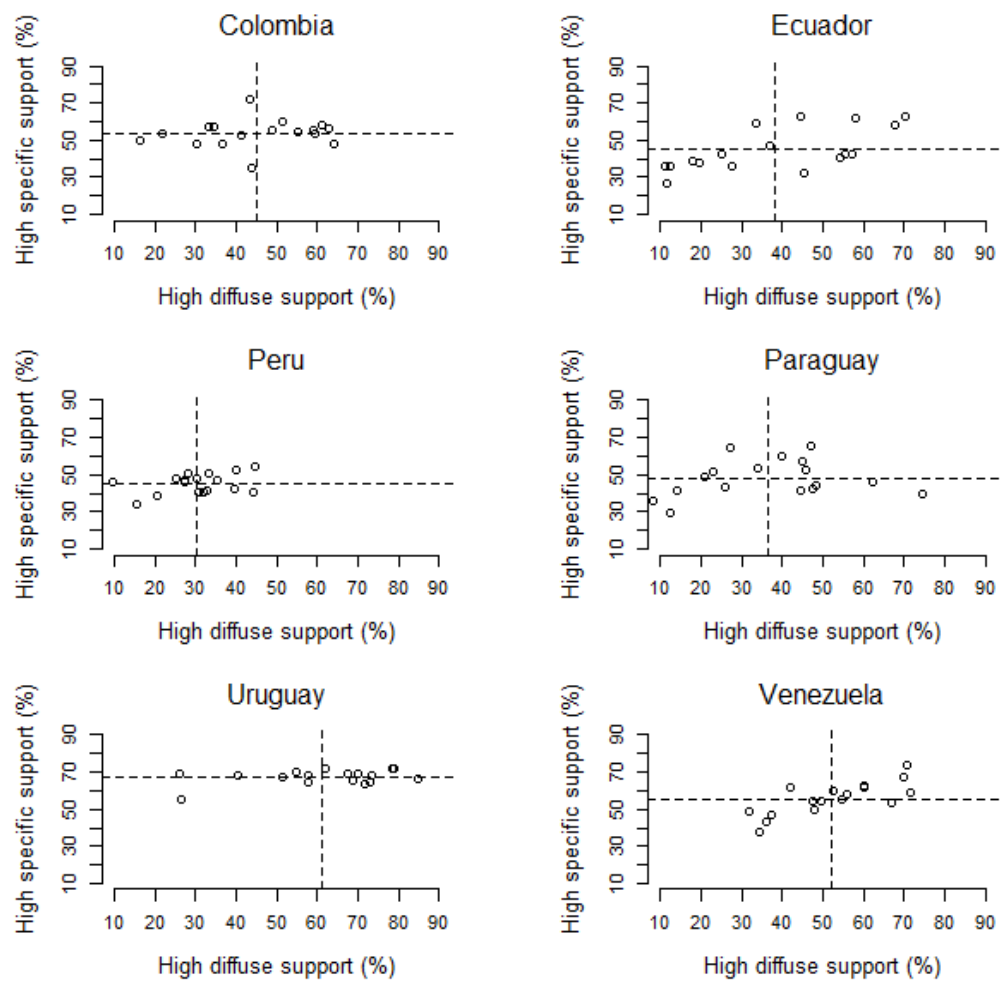

Note: Circles indicate the percentage of individuals classified as having high levels of diffuse and specific support in each South American country. Percentages were calculated over the entire sample period (1996-2015). 
Figure A.7: Marginal Effects of Additional Individual-level Variables on Type Assignment
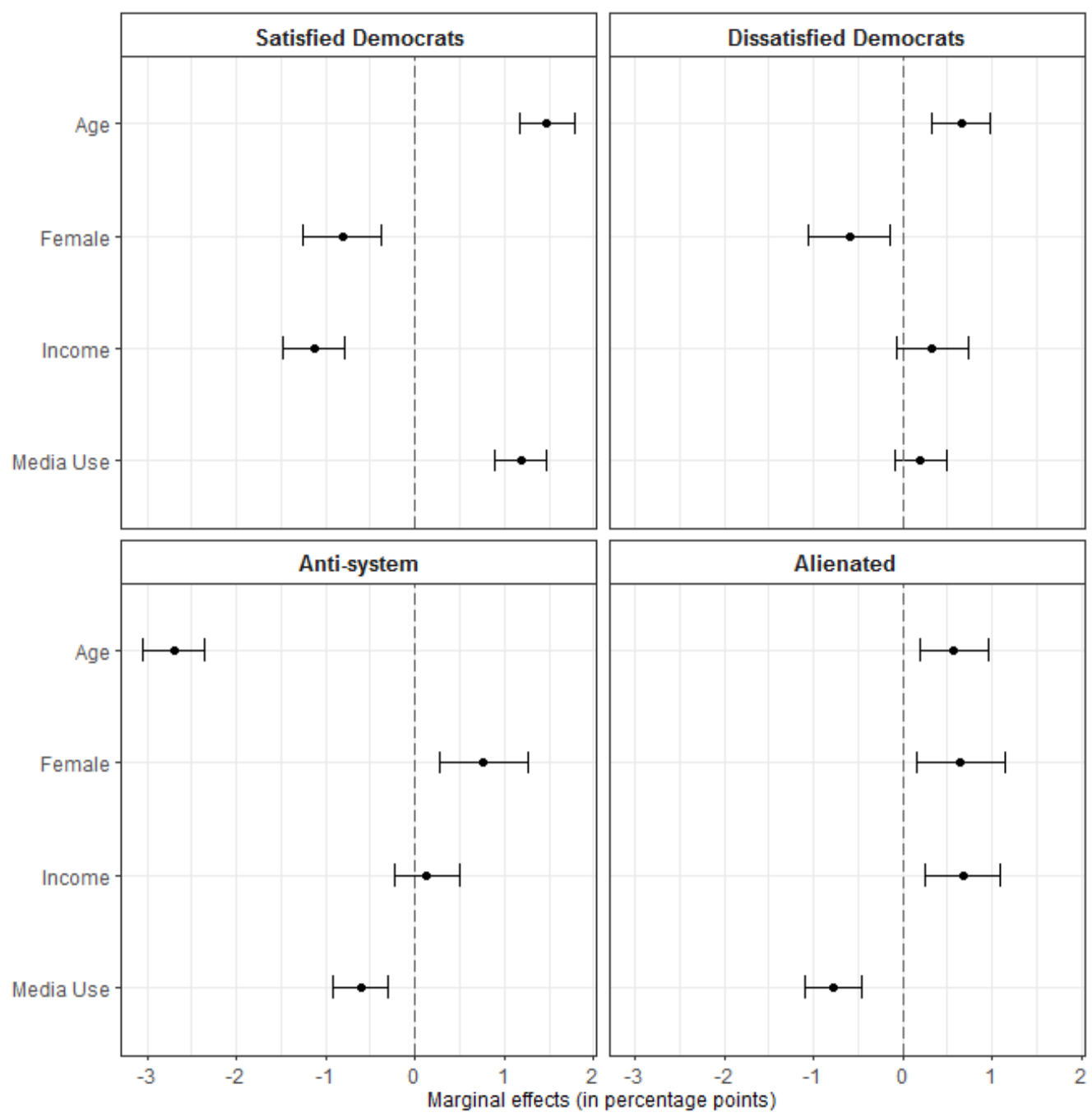

Note: Circles represent the expected change in the probability of assignment to each type associated with a change in the covariates. Horizontal lines give $90 \%$ confidence intervals. 
Figure A.8: Dynamics of Political Support: Andean Countries

Bolivia

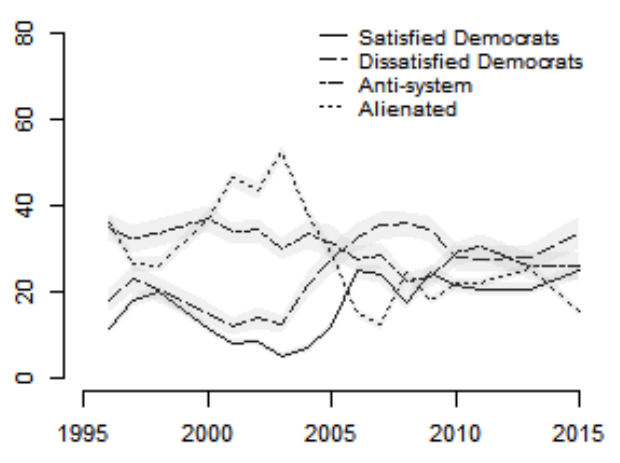

Ecuador

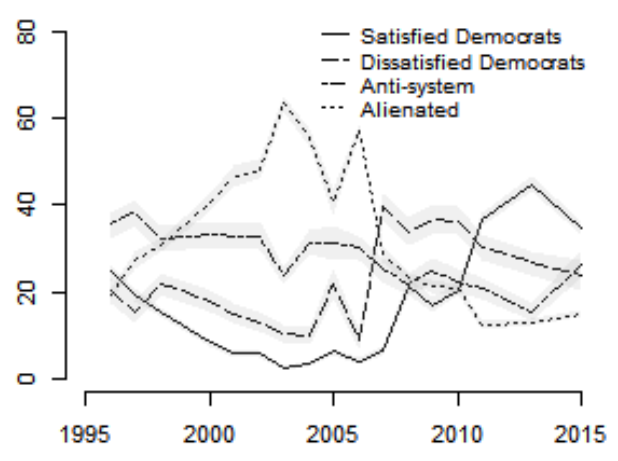

Venezuela

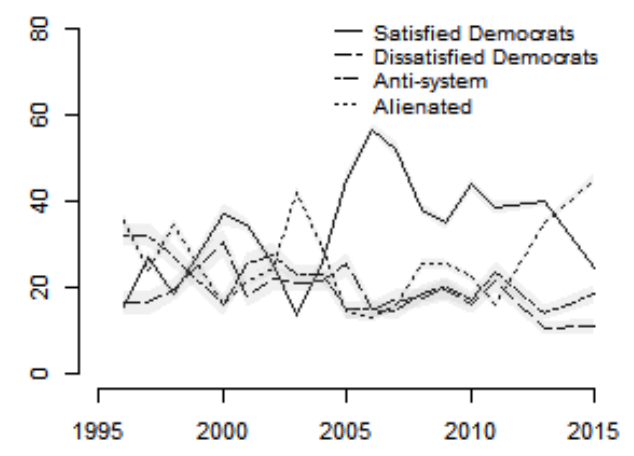

Colombia
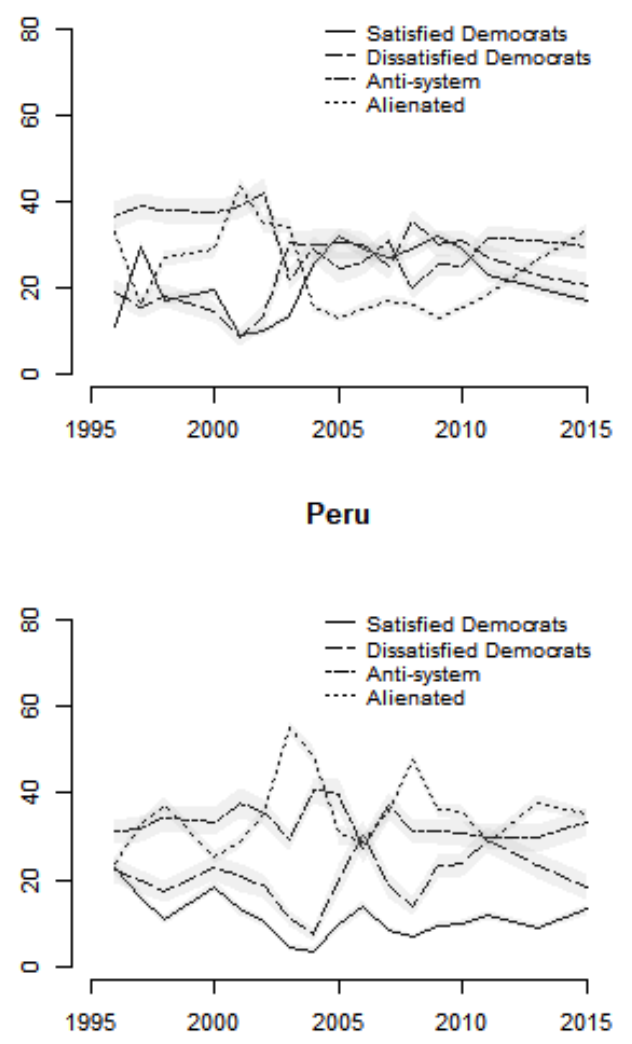

Note: Lines represent the proportion of respondents assigned to each support type in every Andean country between 1996 and 2015. Shaded areas give 90\% confidence intervals for the fraction of respondents allocated to each type. 
Figure A.9: Dynamics of Political Support: Southern Cone Countries

Argentina

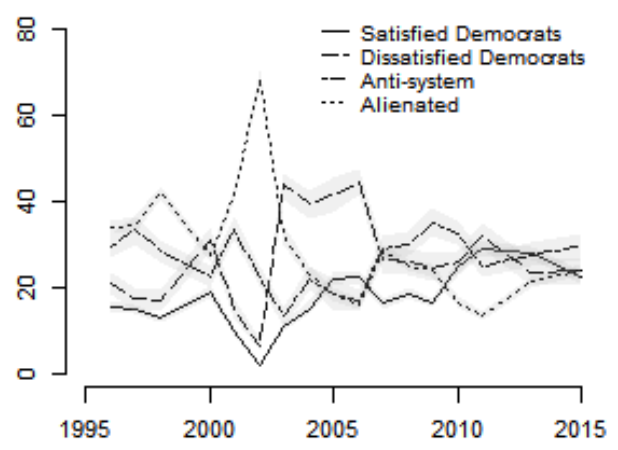

Chile

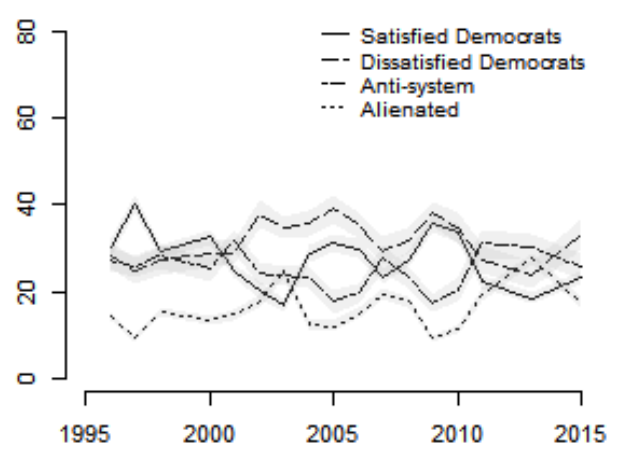

Uruguay

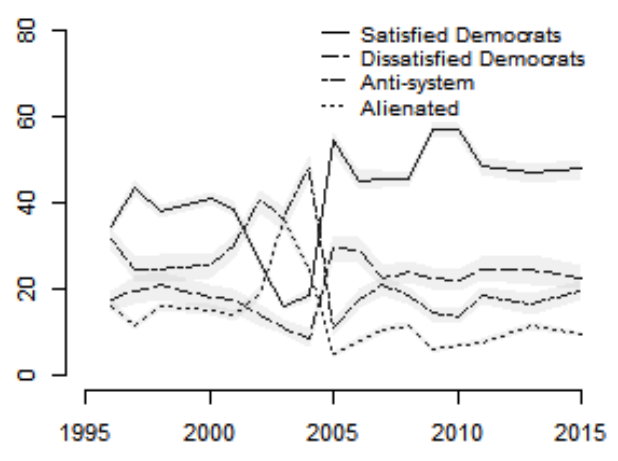

Brazil

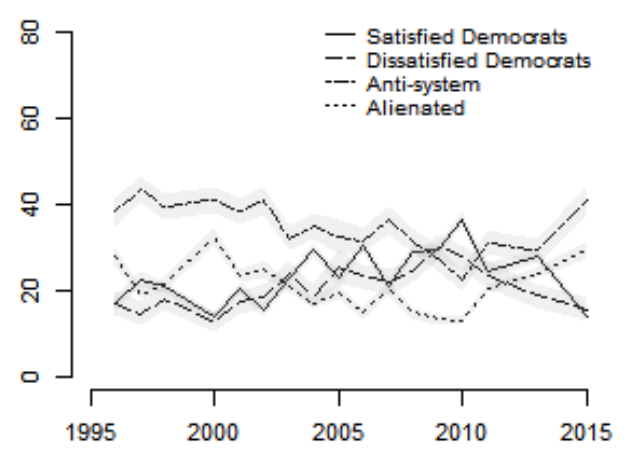

Paraguay

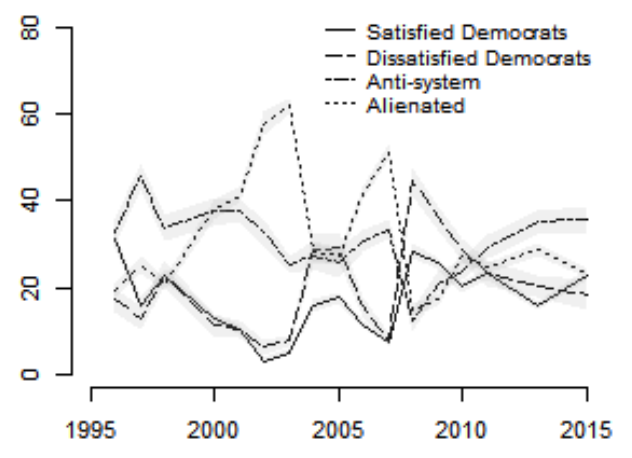

Note: Lines represent the proportion of respondents assigned to each support type in every Southern Cone country between 1996 and 2015. Shaded areas give 90\% confidence intervals for the fraction of respondents allocated to each type. 


\section{C.2 Supplementary Tables}

Table A.2 compares the explanatory power of our chosen model vis-à-vis several alternative mixture models with different number of classes based on various model selection criteria (bootstrapped likelihood ratio test, $\mathrm{BIC}, \mathrm{AIC}, \mathrm{AIC}_{c}$ ) commonly used in the mixture modeling literature (e.g., Hallquist and Wright, 2014). In partic-

ular, we consider whether a more parsimonious representation of differences in survey respondents' attitudes towards political actors, institutions and democracy is able to explain the observed data patters as well as our four-way classification based on Easton (1965)'s theoretical framework. Table A.3, in turn, compares our preferred specification to a simpler model that collapses the diffuse and specific components of political support in a single dimension. Both tables clearly indicate that our preferred empirical specification yields a better fit to the data and enhances the explanatory power of the analysis.

Next, Tables A.4-A.5 complement the information reported in Table 3 of the paper, presenting the distribution of responses across the categories of the survey items included in our empirical analysis among individuals allocated to each support type.

Finally, Tables A.6 and A.7 replicate the results in Tables 3, A.4 and A.5, but using as outcomes four items that were only available for a handful of years and were thus excluded from the main analysis: trust in the state, local government, the public administration, and election authorities. These items enable us to further assess the content-validity and robustness of our classification approach. Consistent with Table 3 of the paper, satisfied democrats generally exhibit the highest scores in all these excluded items, followed by dissatisfied democrats, anti-system, and alienated respondents. 
Table A.2: Model Selection: Comparing Models with Varying Number of Classes

\begin{tabular}{ccccc}
\hline \hline Models & $\begin{array}{c}(1) \\
\text { Log-likelihood }\end{array}$ & $\begin{array}{c}(2) \\
\mathrm{AIC}\end{array}$ & $\begin{array}{c}(3) \\
\mathrm{BIC}\end{array}$ & $\mathrm{AIC}_{c}$ \\
\hline$c_{d}=0, c_{s}=1$ & $\begin{array}{c}237,131.7 \\
(0.00)\end{array}$ & $474,740.7$ & $474,361.4$ & $474,361.7$ \\
& & & & \\
$c_{d}=1, c_{s}=0$ & $-163,018.8$ & $326,524.6$ & $326,137.5$ & $326,137.8$ \\
& $(0.00)$ & & & \\
$c_{d}=1, c_{s}=1$ & -163018.8 & $326,583.0$ & $326,149.5$ & $326,149.9$ \\
& $(0.00)$ & & & \\
$c_{d}=0, c_{s}=2$ & $-151,059.7$ & $302,606.5$ & $302,219.4$ & $302,219.7$ \\
& $(0.00)$ & & & \\
$c_{d}=1, c_{s}=2$ & $-151,059.7$ & $302,674.6$ & $302,233.4$ & $302,233.8$ \\
& $(0.00)$ & & & \\
$c_{d}=2, c_{s}=0$ & $-150,666.1$ & $301,829.1$ & $301,434.3$ & $301,434.6$ \\
& $(0.00)$ & & & \\
$c_{d}=2, c_{s}=1$ & $-150,666.1$ & $301,887.5$ & $301,446.3$ & $301,446.7$ \\
& $(0.00)$ & & & \\
$c_{d}=2, c_{s}=2$ & $-146,378.9$ & $293,322.7$ & $292,873.8$ & $292,874.2$ \\
& $(0.00)$ & & & \\
\hline \hline
\end{tabular}

Notes: The table reports values of various commonly used model selection criteria comparing specifications with varying number of categories for the latent variables representing the diffuse $\left(c_{d}\right)$ and specific $\left(c_{s}\right)$ dimensions of political support. Column (1) presents the log-likelihood for each model and the p-value of the likelihood ratio test (in parenthesis) relative to our preferred specification $\left(c_{d}=2, c_{s}=2\right)$; significant p-values (conventionally $\mathrm{p}<0.05)$ indicate that the more complex model fits the data significantly better than the more parsimonious one (Nylund, Asparouhov, and Muthén, 2007).

Columns (2) and (3) report the values of the Bayesian (BIC) and Akaike (AIC) information criteria for each model. As a "rule of thumb," AIC/BIC differences larger than 10 provide overwhelming evidence in favor of the model with the lower value (see Ntzoufras, 2011, and the references therein).

Column (4) reports the values of the corrected AIC, or $\mathrm{AIC}_{c}$ (Sugiura, 1978), which includes a penalty for the ratio of the number of parameters relative to sample size that helps guard against over-fitting (Hallquist and Wright, 2014).

All the criteria favor our preferred specification. 
Table A.3: Model Comparison: Two-dimensional versus Uni-dimensional Political Support

\begin{tabular}{lcc}
\hline \hline & \multicolumn{2}{c}{ Competing models } \\
& $\begin{array}{c}\text { Two-dimensional } \\
\text { support }\end{array}$ & $\begin{array}{c}\text { Uni-dimensional } \\
\text { support }\end{array}$ \\
\hline $\begin{array}{l}\text { Log-Likelihood } \\
\text { p-value, (bootstrapped) LR test }\end{array}$ & $-146,378.9$ & $-163,018.8$ \\
& \multicolumn{2}{c}{$(0.00)$} \\
Bayesian Information Criterion (BIC) & $293,322.7$ & $326,456.4$ \\
Akaike Information Criterion (AIC) & $292,873.8$ & $326,123.5$ \\
Corrected AIC (AIC $c)$ & $292,874.2$ & $326,123.7$ \\
\hline \hline
\end{tabular}

Notes: The first two rows present the log-likelihood of each model and the p-value of the likelihood ratio test; significant $\mathrm{p}$-values (conventionally $\mathrm{p}<0.05$ ) indicate that the more complex model fits the data significantly better than the more parsimonious one (Nylund, Asparouhov, and Muthén, 2007).

The next two rows report standard information criteria for model comparison. As a "rule of thumb," AIC/BIC differences larger than 10 provide overwhelming evidence in favor of the model with the lower value (see Ntzoufras, 2011, and the references therein).

The bottom row reports the corrected AIC (Sugiura, 1978), which includes a penalty for the ratio of the number of parameters relative to sample size that helps guard against overfitting (Hallquist and Wright, 2014).

All the criteria favor our preferred specification. 
Table A.4: Distribution of Responses to Items Gauging Confidence in Political Actors/Institutions Among Individuals Allocated to each Support Type

\section{Satisfied Democrats}

\begin{tabular}{lcccc} 
Item & Not at all & Little & Some & A lot \\
\hline Government & 1.0 & 11.9 & 52.1 & 34.9 \\
Congress & 1.0 & 10.4 & 65.7 & 22.8 \\
Justice & 1.6 & 14.6 & 59.7 & 24.1 \\
Parties & 8.9 & 29.6 & 50.0 & 11.4 \\
President & 1.1 & 8.0 & 43.7 & 47.2 \\
Military & 5.3 & 14.7 & 47.2 & 32.8 \\
\hline
\end{tabular}

Dissatisfied Democrats

\begin{tabular}{lcccc} 
Item & Not at all & Little & Some & A lot \\
\hline Government & 0.9 & 26.0 & 59.6 & 13.5 \\
Congress & 23.6 & 58.3 & 16.9 & 1.1 \\
Justice & 12.1 & 60.7 & 22.7 & 4.5 \\
Parties & 42.2 & 48.2 & 9.0 & 0.5 \\
President & 1.7 & 18.1 & 54.6 & 25.6 \\
Military & 16.5 & 39.5 & 31.7 & 12.3 \\
\hline
\end{tabular}

Anti-system

\begin{tabular}{lcccc} 
Item & Not at all & Little & Some & A lot \\
\hline Government & 32.4 & 64.6 & 2.9 & 0.0 \\
Congress & 17.8 & 64.6 & 16.2 & 1.4 \\
Justice & 25.2 & 57.6 & 15.9 & 1.3 \\
Parties & 37.1 & 50.7 & 11.2 & 1.0 \\
President & 27.8 & 55.3 & 14.6 & 2.4 \\
Military & 11.2 & 40.7 & 32.3 & 15.8 \\
\hline
\end{tabular}

\begin{tabular}{lcccc} 
& \multicolumn{4}{c}{ Alienated } \\
Item & Not at all & Little & Some & A lot \\
\hline Government & 74.7 & 22.4 & 2.6 & 0.2 \\
Congress & 90.7 & 8.2 & 1.0 & 0.1 \\
Justice & 83.5 & 14.3 & 2.0 & 0.2 \\
Parties & 89.7 & 8.5 & 1.6 & 0.2 \\
President & 67.6 & 22.4 & 7.8 & 2.2 \\
Military & 51.4 & 26.0 & 15.8 & 6.9 \\
\hline
\end{tabular}

Note: Rows indicate the percentage of respondents allocated to each support type reporting a given level of confidence in the corresponding political actor/institution. 
Table A.5: Satisfaction with/Preference for Democracy Among Individuals Allocated to each Support Type

\begin{tabular}{lcccc} 
& \multicolumn{5}{c}{ Satisfied Democrats } \\
Item & Not at all & Little & Some & A lot \\
Satisfaction with democracy & 5.2 & 28.5 & 46.6 & 19.7 \\
& Yes & & & No \\
Prefers democracy over autocracy & 73.2 & & \multicolumn{2}{c}{26.8} \\
\hline \multicolumn{4}{c}{ Dissatisfied Democrats } \\
Item & \multicolumn{1}{c}{ Not at all } & Little & Some & A lot \\
Satisfaction with democracy & 8.0 & 45.3 & 37.9 & 8.9 \\
& Yes & & & No \\
Prefers democracy over autocracy & 72.5 & & & 27.5 \\
\hline
\end{tabular}

\begin{tabular}{lcccc} 
& \multicolumn{4}{c}{ Anti-system } \\
Item & Not at all & Little & Some & A lot \\
Satisfaction with democracy & 23.3 & 54.8 & 19.0 & 2.9 \\
& Yes & & & No \\
Prefers democracy over autocracy & 53.8 & & & 46.2 \\
\hline
\end{tabular}

\begin{tabular}{lcccc} 
& \multicolumn{5}{c}{ Alienated } \\
Item & Not at all & Little & Some & A lot \\
Satisfaction with democracy & 38.5 & 46.2 & 12.5 & 2.8 \\
& Yes & & & No \\
Prefers democracy over autocracy & 55.2 & & & 44.8 \\
\hline
\end{tabular}

Note: For each support type, the first row indicates the percentage of respondents expressing a given level of satisfaction with democracy. The second row displays the percentage of respondents who did/did not manifest always preferring democracy over autocracy. 
Table A.6: Relationship between Estimated Types and Excluded Trust Items

\begin{tabular}{lcccc} 
& \multicolumn{4}{c}{ Satisfied Democrats } \\
Item & Average & Difference & $5 \%$ & $95 \%$ \\
\hline State & 3.02 & 0.79 & 0.78 & 0.80 \\
Public administration & 2.86 & 0.75 & 0.74 & 0.76 \\
Local government & 2.92 & 0.74 & 0.73 & 0.75 \\
Election authority & 3.03 & 0.72 & 0.71 & 0.73 \\
\hline
\end{tabular}

\begin{tabular}{lcccc} 
& \multicolumn{4}{c}{ Dissatisfied Democrats } \\
Item & Average & Difference & $5 \%$ & $95 \%$ \\
\hline State & 2.42 & 0.19 & 0.19 & 0.20 \\
Public administration & 2.15 & 0.04 & 0.03 & 0.05 \\
Local government & 2.24 & 0.05 & 0.04 & 0.06 \\
Election authority & 2.37 & 0.07 & 0.06 & 0.08 \\
\hline
\end{tabular}

\begin{tabular}{lcccc} 
& \multicolumn{4}{c}{ Anti-system } \\
Item & Average & Difference & $5 \%$ & $95 \%$ \\
\hline State & 2.08 & -0.15 & -0.16 & -0.15 \\
Public administration & 2.07 & -0.04 & -0.05 & -0.03 \\
Local government & 2.13 & -0.05 & -0.06 & -0.05 \\
Election authority & 2.25 & -0.06 & -0.06 & -0.05 \\
\hline
\end{tabular}

\begin{tabular}{lcccc} 
& \multicolumn{4}{c}{ Alienated } \\
Item & Average & Difference & $5 \%$ & $95 \%$ \\
\hline State & 1.52 & -0.71 & -0.72 & -0.70 \\
Public administration & 1.44 & -0.67 & -0.67 & -0.66 \\
Local government & 1.54 & -0.65 & -0.66 & -0.64 \\
Election authority & 1.66 & -0.65 & -0.65 & -0.64 \\
\hline
\end{tabular}

Note: For each support type, the table reports within-class averages for each excluded trust item (first column) and differences with respect to the overall (sample) average (second column). The third and fourth columns report $90 \%$ confidence intervals for this difference. 
Table A.7: Detailed Distribution of Responses to Excluded Trust Items Among Individuals Allocated to each Support Type

\begin{tabular}{|c|c|c|c|c|}
\hline \multirow[b]{2}{*}{ Item } & \multicolumn{4}{|c|}{ Satisfied Democrats } \\
\hline & Not at all & Little & Some & A lot \\
\hline State & 2.1 & 17.7 & 56.1 & 24.1 \\
\hline Public administration & 3.0 & 24.1 & 56.9 & 16.0 \\
\hline Local government & 3.9 & 21.6 & 52.7 & 21.8 \\
\hline \multirow[t]{2}{*}{ Election authority } & 3.1 & 18.8 & 50.4 & 27.7 \\
\hline & \multicolumn{4}{|c|}{ Dissatisfied Democrats } \\
\hline Item & Not at all & Little & Some & A lot \\
\hline State & 11.0 & 41.8 & 41.0 & 6.2 \\
\hline Public administration & 18.6 & 50.4 & 28.8 & 2.2 \\
\hline Local government & 18.2 & 44.7 & 32.2 & 4.8 \\
\hline \multirow[t]{2}{*}{ Election authority } & 16.1 & 38.6 & 37.1 & 8.2 \\
\hline & \multicolumn{4}{|c|}{ Anti-system } \\
\hline Item & Not at all & Little & Some & A lot \\
\hline State & 23.1 & 48.8 & 25.5 & 2.6 \\
\hline Public administration & 20.9 & 53.3 & 24.1 & 1.8 \\
\hline Local government & 21.3 & 48.0 & 26.7 & 4.0 \\
\hline \multirow[t]{2}{*}{ Election authority } & 19.3 & 43.0 & 31.2 & 6.5 \\
\hline & \multicolumn{4}{|c|}{ Alienated } \\
\hline Item & Not at all & Little & Some & A lot \\
\hline State & 57.1 & 34.4 & 7.8 & 0.6 \\
\hline Public administration & 61.2 & 33.6 & 4.9 & 0.2 \\
\hline Local government & 57.8 & 31.9 & 9.2 & 1.1 \\
\hline Election authority & 50.2 & 35.0 & 13.3 & 1.5 \\
\hline
\end{tabular}

Note: Rows indicate the percentage of individuals assigned to each support type reporting a given level of confidence in the state, in local government, in the public administration, and in election authorities. 


\section{Additional References}

Amarante, V., Vigorito, A. 2006. Evolución de la pobreza y la desigualdad en Uruguay, 2001-2006. Available at http://www.ine.gub.uy/documents/10181/35933/ Informe+final+pobreza+y+desigualdad.pdf/aecc610e-731b-44fc-a4ce-f6a5124c67c6, accessed 12 July 2017.

Arguello, A.K., Lemus, M.L., Sánchez, C. 2007. Distribución de la Riqueza en Colombia durante la Apertura Económica. Universidad de San Buenaventura, Bogota. Available at http://biblioteca.usbbog.edu.co:8080/Biblioteca/BDigital/ 41128.pdf, accessed 15 July 2017.

Baker, A. 2016. Latin American Election Results with Party Ideology Scores 2.0. Available at http://spot.colorado.edu/ bakerab/data.html, accessed 20 June 2017.

Catholic University of Argentina. 2017. Observatorio de la Deuda Social Argentina. Available at www.uca.edu.ar/observatorio, accessed 1 July 2017.

Cesi, C., Keefer, P., Scartascini, C. 2016. Database of Political Institutions, Inter-American Development Bank. Available at https://publications.iadb.org/ handle/11319/7408, accessed 15 June 2017.

Córdova, A., Seligson, M.A. 2009. Economic Crisis and Democracy in Latin America. Pol. Sci. \& Polit. 42, 673-678.

Di Santi, M. 2016. Cómo evolucionó la pobreza según estas fuentes alternativas al INDEC? Chequeado - La Verificación del Discurso Público. Available at http: //chequeado.com/el-explicador/, accessed 18 June 2017.

Economic Commission for Latin America and the Caribbean. 2017. CEPALSTAT: Databases and Statistical Publications. Available at http://estadisticas cepal. org/cepalstat/WEB_CEPALSTAT/estadisticasIndicadores.asp? idioma=i, accessed 20 June 2017.

Freedom House. 2017. Freedom in the World 2017. Available at https:// freedomhouse.org/report-types/freedom-world, accessed 12 June 2017. 
Gallagher, M. 1991. Proportionality, Disproportionality and Electoral Systems. Elec. Stud. 10, 33-51.

Gallagher, M. 2016. Electoral systems web site. Available at http://www.tcd. ie/Political_Science/staff/michael_gallagher/ElSystems/, accessed 25 June 2017.

Gandrud, C. 2015. Gallagher Electoral Disproportionality Data: 121 Countries, 1945-2014. Available at http://christophergandrud.github.io/Disproportionality_ Data/, accessed 10 July 2017.

Hallquist, M.N., Wright, A.G. 2014. Mixture Modeling Methods for the Assessment of Normal and Abnormal Personality I: Cross-sectional Models. J. Pers. Assess. 96, 256-268.

Inter-American Development Bank. 2017. Numbers for Development. Available at https://data.iadb.org/, accessed 12 June 2017.

Izquierdo, I., Talvi, E. 2009. Policy Trade-offs for Unprecedented Times: Confronting the Global Crisis in Latin America and the Caribbean. Inter-American Development Bank, Washington, D.C.

Laakso, M., Taagepera, R. 1979. Effective Number of Parties: A Measure with Application to West Europe. Comp. Pol. Stud. 12, 3-27.

Latinobarometer Surveys, 1996-2015. Available at http://www. latinobarometro. org/, accessed 15 January 2015.

Ministry of Economics and Finance, Bolivia. 2011. Noticias del Ministerio. Available at http://www.economiayfinanzas.gob.bo/index.php?opcion=com_prensa\& ver=prensa\&id=1847\&seccion=306\&categoria=5, accessed 16 July 2017.

Ministry of Popular Planning, Venezuela. 2015. Venezuela en Cifras. Available at http://www.mppp.gob.ve/libro/mayo_pdf/VzlaEnCifras\%2005-2015.pdf, accessed 11 July 2017.

National Statistics Institute of Uruguay. 2016. Estimación de la Pobreza por el Método del Ingreso. Available at http://www.ine.gub.uy/documents/10181/ 
364159/Estimaci\%C3\%B3n+de+la+pobreza+por+el+M\%C3\%A9todo+del+Ingreso+2015/ 321a0edb-d97e-4ab0-aa88-e31ce7a22307, accessed 10 July 2017.

Ntzoufras, I. 2011. Bayesian Modeling using WinBUGS. John Wiley \& Sons, Hoboken.

Nylund, K.L., Asparouhov, T., Muthén, B.0. 2007. Deciding on the Number of Classes in Latent Class Analysis and Growth Mixture Modeling: A Monte Carlo Simulation Study. Struc. Eq. Model. 14, 535-569.

Polity IV Project. 2016. Polity IV Annual Time-Series, 1800-2015. Available at http://www.systemicpeace.org/inscrdata.html, accessed 20 February 2015.

Roberts, K. 2008. The Mobilization of Opposition to Economic Liberalization. An. Rev. Pol. Sci. 11, 327-349.

Sugiura N. 1978. Further Analysis of the Data by Akaike's Information Criterion and the Finite Corrections. Comm. in Stat. 10, 333-340.

SUMATE. 2016. Venezuela en Cifras Oficiales. Available at http://venezuelareal . zoomblog. com/archivo/2006/11/23/nueva-Publicacion-De-Sumate-Venezuela- . html, accessed 11 July 2017.

V-Dem, Varieties of Democracy. 2017. V-Dem Data, Version 7.1. Available at https://www.v-dem.net/en/data/data-version-7-1/, accessed 18 June 2017.

World Bank. 2017. World Development Indicators. Available at http://databank . worldbank .org/data/reports . aspx?source=world-development-indicators, accessed 15 June 2017. 